\title{
Sensitivity analysis of methane emissions derived from SCIAMACHY observations through inverse modelling
}

\author{
J. F. Meirink ${ }^{1, *}$, H. J. Eskes ${ }^{1}$, and A. P. H. Goede ${ }^{1}$ \\ ${ }^{1}$ Climate Research and Seismology Department, Royal Netherlands Meteorological Institute (KNMI), De Bilt, The \\ Netherlands \\ *now at: Institute for Marine and Atmospheric research Utrecht (IMAU), Utrecht University, Utrecht, The Netherlands
}

Received: 22 August 2005 - Published in Atmos. Chem. Phys. Discuss.: 29 September 2005

Revised: 31 January 2006 - Accepted: 14 Februrary 2006 - Published: 24 April 2006

\begin{abstract}
Satellite observations of trace gases in the atmosphere offer a promising method for global verification of emissions and improvement of global emission inventories. Here, an inverse modelling approach based on fourdimensional variational (4D-var) data assimilation is presented and applied to synthetic measurements of atmospheric methane. In this approach, emissions and initial concentrations are optimised simultaneously, thus allowing inversions to be carried out on time scales of weeks to months, short compared with the lifetime of methane. Observing System Simulation Experiments (OSSEs) have been performed to demonstrate the feasibility of the method and to investigate the utility of SCIAMACHY observations for methane source estimation. The impact of a number of parameters on the error in the methane emission field retrieved has been analysed. These parameters include the measurement error, the error introduced by the presence of clouds, and the spatial resolution of the emission field. It is shown that $4 \mathrm{D}$-var is an efficient method to deal with large amounts of satellite data and to retrieve emissions at high resolution. Some important conclusions regarding the SCIAMACHY measurements can be drawn. (i) The observations at their estimated precision of 1.5 to $2 \%$ will contribute considerably to uncertainty reduction in monthly, subcontinental $(\sim 500 \mathrm{~km})$ methane source strengths. (ii) Systematic measurement errors well below $1 \%$ have a dramatic impact on the quality of the derived emission fields. Hence, every effort should be made to identify and remove such systematic errors. (iii) It is essential to take partly cloudy pixels into account in order to achieve sufficient spatial coverage. (iv) The uncertainty in measured cloud parameters may at some point become the limiting factor for methane emission retrieval, rather than the uncertainty in measured methane itself.
\end{abstract}

Correspondence to: J. F. Meirink

(j.f.meirink@phys.uu.nl)

\section{Introduction}

Methane $\left(\mathrm{CH}_{4}\right)$ and carbon dioxide $\left(\mathrm{CO}_{2}\right)$ are the most important anthropogenic greenhouse gases. Atmospheric methane concentrations have increased by around $150 \%$ since pre-industrial times. This corresponds with an estimated radiative forcing of $0.48 \mathrm{~W} \mathrm{~m}^{-2}$, which amounts to $20 \%$ of the total radiative forcing due to well-mixed greenhouse gases (IPCC, 2001; Lelieveld et al., 1998). Apart from this direct forcing there are also indirect greenhouse effects through chemistry: increases in $\mathrm{CH}_{4}$ lead to higher levels of tropospheric ozone and stratospheric water vapour. Finally, changes in $\mathrm{CH}_{4}$ influence the oxidising capacity of the atmosphere.

More than half of the present-day methane emissions are of anthropogenic origin, the most important sources being fossil-fuel production, domestic ruminants, rice cultivation and waste handling (e.g., Lelieveld et al., 1998). Natural emissions originate mainly from wetlands. The uncertainties of the fluxes in most of these categories are of the order of $50 \%$ on the global scale and may be larger on regional scales. The atmospheric growth rate of methane has large variability, and the causes of this variability are subject of considerable debate. Thus, improved knowledge of methane source distributions is needed to quantitatively understand observed changes in atmospheric concentrations. From a political point of view, assessment and monitoring of emissions is required in response to the Kyoto Protocol, which calls for a reduction in greenhouse gas emissions by the year 2010 .

Existing estimates of methane sources can be improved by inverse modelling, using a transport model to infer emissions from measured atmospheric concentrations. This technique has been extensively applied using surface observations (Hein et al., 1997; Houweling et al., 1999; Chen, 2003; Dentener et al., 2003; Butler et al., 2004; Mikaloff Fletcher et al., 2004a,b; Bergamaschi et al., 2005). However, surface

Published by Copernicus GmbH on behalf of the European Geosciences Union. 
measurements are only available from a limited number of monitoring stations, mainly at remote locations. The large distance between methane sources and the observation locations combined with atmospheric mixing causes an entanglement of signals from different source regions. As a result, the observations contain statistically significant information on emissions only on (sub-)continental scales at best (Houweling et al., 1999). Surface observations are also available at locations with nearby emissions. These measurements have a more direct relation with the sources, and are thus useful for estimating regional-scale source strengths (Bergamaschi et al., 2005), although the correct representation of these measurements by transport models remains a challenge. Specifically, if measurements are influenced by local sources, their interpretation is difficult.

Satellite observations hold a future promise to overcome these problems because of their global coverage and their large sampling volumes, thus posing less representativity problems. Methane has been measured from space both in limb (forward) and in nadir (downward) mode. Limb observations (e.g., Randel et al., 1998) are mainly restricted to the stratosphere, and thus contain hardly any information on the distribution of surface sources. Nadir observations of atmospheric methane were made by the IMG (Interferometric Monitor for Greenhouse gases) instrument on board ADEOS (ADvanced Earth Observing Satellite) (Clerbaux et al., 2003). However, being an infrared spectrometer, IMG is relatively insensitive to the lower troposphere, and the relation between measured concentrations anomalies and their source is rather indirect. Recently, satellite observations of methane in the near-infrared region have become available from the SCIAMACHY (SCanning Imaging Absorption spectroMeter for Atmospheric CHartographY) instrument (Goede et al., 1991; Bovensmann et al., 1999) on board ESA (European Space Agency)'s environmental satellite ENVISAT, launched 1 March 2002 (Buchwitz et al., 2005; Frankenberg et al., 2005a). In the near infrared most sunlight reaching the satellite has been backscattered by the Earth's surface, resulting in measurements with an almost constant sensitivity from the stratosphere down to the boundary layer.

Methane is a well-mixed greenhouse gas, with a lifetime of around 10 years. Hence, the variability in its concentration is small. Total column measurements must have a high precision (of the order of $1 \%$ ) in order to be useful. It is a challenge to achieve such precisions. In addition, there are many factors that may lead to systematic biases in the observations, such as errors in the assumed vertical profiles of pressure, temperature, and water vapour (e.g., Frankenberg et al., 2005b), uncertainties in the presence and characterisation of clouds and aerosols, errors in the calibration of radiance measurements, and uncertainties in spectroscopic reference data or instrumental parameters, such as the detector slit function (Gloudemans et al., 2005).
Inverse modelling of trace gas emissions from satellite measurements has been restricted so far to shorter-lived species such as $\mathrm{NO}_{2}$ (Martin et al., 2003), $\mathrm{CO}$ (Pétron et al., 2004), and the combination of both (Müller and Stavrakou, 2005). Concerning long-lived greenhouse gases, only synthetic studies have been reported, limited to $\mathrm{CO}_{2}$ so far. Rayner et al. (2002) investigated the utility of $\mathrm{CO}_{2}$ satellite observations for inverse modelling, and specifically assessed the influence of satellite orbit, scan geometry and clouds. In addition, Houweling et al. (2004) compared the potential benefits of three different - existing and planned - satellite instruments measuring $\mathrm{CO}_{2}$.

In this paper we present a method for deriving $\mathrm{CH}_{4}$ emissions from satellite measurements. The method is based on four-dimensional variational (4D-var) data assimilation. 4Dvar has been extensively applied in numerical weather prediction (e.g., Talagrand and Courtier, 1987). Fisher and Lary (1995) introduced the technique in the field of atmospheric chemistry. Eskes et al. (1999) used 4D-var for the assimilation of total ozone measurements from the GOME (Global Ozone Monitoring Experiment) satellite instrument.

The conventional synthesis technique is computationally only feasible if one of two conditions is satisfied. (i) Relatively few parameters are optimised. This is the the so-called big-region approach, which has the disadvantage that it introduces aggregation errors (Kaminski et al., 2001; Engelen et al., 2002). (ii) Relatively few measurements are considered. In this case, the sensitivity of each individual measurement to the emissions may be calculated with an adjoint model. In contrast, satellite instruments such as SCIAMACHY produce a large volume of data at always changing locations, for which the conventional synthesis approach is not appropriate. Pre-averaging the measurements to weekly or monthly means over large regions results in a loss of information on the smaller scale, both in time and in space. On the other hand, 4D-var efficiently handles large volumes of data, and is thus particularly well suited for inverse modelling of satellite data.

Since satellites provide high temporal and spatial resolution measurements of atmospheric concentrations, it is possible, in principle, to resolve emissions on time scales of weeks to months and regional spatial scales, when the observations are accurate enough. A problem may arise when inversions over short $(<\sim 1$ month) time scales are attempted. In this case, the influence of the initial condition on the methane concentrations during the assimilation window cannot be neglected (Peylin et al., 2005). Fortunately, this problem can be solved in an elegant way within the $4 \mathrm{D}$-var scheme, by taking not only the emissions but also the initial concentrations as parameters to be optimized. The feasibility of this approach in air quality models was demonstrated by Elbern and Schmidt (2002). In this study we will show, using simulated SCIAMACHY measurements, that it is possible to distinguish between errors in initial concentrations and emissions. 
Table 1. $\mathrm{CH}_{4}$ emissions employed in this study. Global totals are presented both per year and for the month March. Notes are: ${ }^{1}$ EDGAR version 3.2, year 1995; ${ }^{2}$ landfills scaled to $40 \mathrm{Tg} \mathrm{yr}^{-1} ;{ }^{3} 5$-year average of the period 1997-2001, with total forest burning scaled to $20 \mathrm{Tg}^{-1}$ and savanna burning to $15 \mathrm{Tg} \mathrm{yr}^{-1} ;{ }^{4} 15$-year mean field.

\begin{tabular}{|c|c|c|c|}
\hline \multirow[t]{2}{*}{ Source category } & \multirow[t]{2}{*}{ Reference } & \multicolumn{2}{|c|}{ Emission $\left(\mathrm{Tg} \mathrm{CH}_{4} \mathrm{yr}^{-1}\right)$} \\
\hline & & Year & March \\
\hline \multicolumn{4}{|c|}{ Anthropogenic } \\
\hline Domestic ruminants & EDGAR $^{1}$ & 89 & 89 \\
\hline Fossil fuel production & EDGAR $^{1}$ & 87 & 87 \\
\hline Waste treatment & $\mathrm{EDGAR}^{1,2}$ & 73 & 73 \\
\hline Rice cultivation & Matthews et al. (1987) & 60 & 28 \\
\hline Biomass burning & Olivier et al. $(2003)^{3}$ & 35 & 33 \\
\hline Biofuel & EDGAR $^{1}$ & 14 & 14 \\
\hline Minor sources & EDGAR $^{1}$ & 5 & 5 \\
\hline \multicolumn{4}{|c|}{ Natural } \\
\hline Wetlands & Walter et al. $(2001)^{4}$ & 155 & 138 \\
\hline Termites & Sanderson (1996) & 20 & 20 \\
\hline Ocean & Houweling et al. (1999) & 15 & 15 \\
\hline Wild animals & Houweling et al. (1999) & 5 & 5 \\
\hline Volcanoes & Houweling et al. (1999) & 4 & 4 \\
\hline Soil sink & Ridgwell et al. (1999) & -30 & -25 \\
\hline Total & & 532 & 486 \\
\hline
\end{tabular}

The goal of this paper is twofold: (i) to present and illustrate the inverse modelling methodology for methane; (ii) to assess the utility of SCIAMACHY measurements for estimating $\mathrm{CH}_{4}$ sources. This has been achieved by performing a series of so-called Observing System Simulation Experiments (OSSEs). The dependence of the inversion result on a number of variables, such as errors in the measurement of $\mathrm{CH}_{4}$ and cloud parameters, the resolution of the inversion and a priori errors in the emission field, is investigated. Our method can similarly be employed to define requirements for future near-infrared satellite instruments for $\mathrm{CH}_{4}$ source attribution.

The paper is structured as follows. In Sect. 2, the methodology is outlined. This includes descriptions of the transport model (Sect. 2.1), the 4D-var method (Sect. 2.2), the satellite data (Sect. 2.3), and the set-up of the OSSE experiments (Sect. 2.4). In Sect. 3, the results of the experiments are discussed. Finally, Sect. 4 contains conclusions and recommendations for future research.

\section{Method}

\subsection{Model}

The model used in the present study is the global chemistrytransport model TM4 (Dentener et al., 2003, and references therein). The model is run on a spatial resolution of $3^{\circ} \times 2^{\circ}$, with 25 hybrid $\sigma$-pressure layers in vertical direction up to
$0.1 \mathrm{hPa}$. It is driven by six-hourly meteorological fields from the European Centre for Medium Range Weather Forecast (ECMWF) operational data. These fields include global distributions for horizontal wind, surface pressure, temperature, humidity, liquid and ice water content, cloud cover and precipitation. Key processes included are mass-conserved tracer advection, convective tracer transport, boundary-layer diffusion, photolysis, dry and wet deposition as well as tropospheric chemistry including non-methane hydrocarbons to account for chemical loss by reaction with $\mathrm{OH}$ (Houweling et al., 1998). Except for methane, anthropogenic emissions are based on Van Aardenne et al. (2001), which is in turn based on the widely used EDGAR (Emission Database for Global Atmospheric Research) database (Olivier et al., 1999), while natural emissions are as in Houweling et al. (1998).

Differences between the model versions employed here and in Dentener et al. (2003) are: (i) A mass-conserving preprocessing of the meteorological input is applied according to Bregman et al. (2003); (ii) the stratospheric destruction of methane by reaction with $\mathrm{OH}, \mathrm{Cl}$ and $\mathrm{O}\left({ }^{1} D\right)$ is taken into account by applying correction factors to the model-calculated destruction rate based on a 2-D-model (G. Velders, personal communication); (iii) $\mathrm{CH}_{4}$ concentrations above $50 \mathrm{hPa}$ are nudged to the monthly-mean zonal HALOE/CLAES climatology from UARS (Randel et al., 1998); (iv) $\mathrm{CH}_{4}$ emissions are as described in Table 1. 
The inverse modelling experiments are done with a single tracer version of TM4. In this version, $\mathrm{CH}_{4}$ oxidation is prescribed by monthly-mean $\mathrm{OH}$ fields with a 3-hourly resolution of the diurnal cycle, which are extracted from a fullchemistry simulation. Additionally, the tracer version contains $\mathrm{CH}_{4}$ sources and stratospheric sinks (including nudging to HALOE/CLAES data) as described above. It has been verified that $\mathrm{CH}_{4}$ columns simulated by the single tracer version differ less than $0.2 \%$ from the full-chemistry version over a 1-month simulation period. For the data assimilation an adjoint model of the single tracer version has been constructed.

\subsection{Inversion method}

The $\mathrm{CH}_{4}$ source estimation is based on four-dimensional variational (4D-var) data assimilation (e.g., Talagrand and Courtier, 1987). The 4D-var technique involves the minimisation of a cost function $J$ with respect to a control variable $\boldsymbol{x}_{0}$. The control variable is the value of the model state $\boldsymbol{x}$ at the start of the assimilation window, which is taken as one month here. In our case, $\boldsymbol{x}$ consists of the of the two-dimensional $\mathrm{CH}_{4}$ surface emission field $s$ along with the three-dimensional atmospheric $\mathrm{CH}_{4}$ concentration field $\boldsymbol{c}: \boldsymbol{x}=(\boldsymbol{s}, \boldsymbol{c})$. The cost function is defined as:

$$
\begin{aligned}
J\left(x_{0}\right) & =\frac{1}{2}\left(\boldsymbol{x}_{0}-\boldsymbol{x}_{b}\right)^{T} \mathbf{B}^{-1}\left(\boldsymbol{x}_{0}-\boldsymbol{x}_{b}\right)+ \\
& +\frac{1}{2} \sum_{i=0}^{n}\left(\mathbf{H}_{i} \boldsymbol{x}_{i}-\boldsymbol{y}_{i}\right)^{T} \mathbf{R}_{i}^{-1}\left(\mathbf{H}_{i} \boldsymbol{x}_{i}-\boldsymbol{y}_{i}\right) .
\end{aligned}
$$

The first term in Eq. (1) is the background term, which measures the deviation of the control variable from its background $\boldsymbol{x}_{b}$ (also called a priori); the second term is the observation term, which measures the deviation of the model simulation from observations during the time window of the assimilation. The observations at time $t_{i}$ are denoted by $\boldsymbol{y}_{i}$. The observation operators $\mathbf{H}_{i}$ translate the model state $\boldsymbol{x}_{i}$ at time $t_{i}$ to "model equivalents" of the observations. These operators include horizontal interpolation from the model grid points to the locations of the satellite measurements and subsequent vertical integration taking into account the averaging kernels of the satellite measurements (see Sect. 2.3). The background error covariance matrix $\mathbf{B}$ consists of the covariances of expected errors in $\boldsymbol{x}_{b}$. The observation error covariance matrices $\mathbf{R}_{i}$ consist of the covariances of expected errors in $\boldsymbol{y}_{i}$. These error covariance matrices are crucial ingredients of the assimilation system. They determine the relative weight given to the observations relative to the background model estimate. Additionally, spatial correlations in the background error covariance matrix determine how information from the observations is smoothed in the analysis increments $\boldsymbol{x}_{0}-\boldsymbol{x}_{b}$.

The model state at a given time is a function of the initial model state:

$\boldsymbol{x}_{i}=\mathbf{M}_{i-1} \boldsymbol{x}_{i-1}=\mathbf{M}_{i-1} \cdots \mathbf{M}_{0} \boldsymbol{x}_{0}$ where $\mathbf{M}_{i}$ denotes integration of the model from time $i$ to time $i+1$. The model operator includes both the forward tracer transport model and a flux model. We assume the emissions to be constant throughout the assimilation window, so that the flux model is simply the identity matrix. Note that both $\mathbf{M}_{i}$ and $\mathbf{H}_{i}$ can be written as matrices, since they represent linear operators in the present study.

In order to minimise the cost function, its gradient with respect to the control vector is needed:

$$
\begin{aligned}
\nabla J\left(\boldsymbol{x}_{0}\right) & =\mathbf{B}^{-1}\left(\boldsymbol{x}_{0}-\boldsymbol{x}_{b}\right)+ \\
& +\sum_{i=0}^{n} \mathbf{M}_{0}^{T} \cdots \mathbf{M}_{i-1}^{T} \mathbf{H}_{i}^{T} \mathbf{R}_{i}^{-1}\left(\mathbf{H}_{i} \boldsymbol{x}_{i}-\boldsymbol{y}_{i}\right) .
\end{aligned}
$$

The gradient includes the adjoint model operators $\mathbf{M}_{i}^{T}$. It is efficiently calculated by performing one integration of the adjoint model, starting with a zero field, and adding measurement innovations at each measurement time. The minimisation is performed iteratively using the quasi-Newton routine m1qn3 (Gilbert and Lemaréchal, 1989).

The convergence to the minimum of the cost function can be considerably improved when pre-conditioning is applied (Courtier et al., 1994). To this end, a transformation of the control vector is defined as $\boldsymbol{x}_{b}-\boldsymbol{x}=\mathbf{A} \boldsymbol{w}$, where $\mathbf{B}=\mathbf{A} \mathbf{A}^{T}$. With this transformation the background part of the cost function becomes simply $J_{b}=\frac{1}{2} \boldsymbol{w}^{T} \boldsymbol{w}$. Note that this pre-conditioning has the additional advantage that $\mathbf{B}$ does not have to be inverted. At the start of every forward integration we only need to multiply $\boldsymbol{w}$ with $\mathbf{A}$, while at the end of every adjoint iteration the observation part of the gradient needs to be multiplied with $\mathbf{A}^{T}$. Hence, we specify $\mathbf{A}$ rather than $\mathbf{B}$.

The background error covariance matrix is created as follows. For the emission part, the variances are assumed to be proportional to the emissions themselves: $\sigma_{\boldsymbol{s}} \sim \boldsymbol{s}$. Errors in emissions are assumed to be correlated over a distance defined by the decorrelation length scale $L_{s}$. Accordingly, the correlations are modelled by a Gaussian function of the distance between grid cells. This scale defines the effective resolution of the emission analysis.

For the concentration part, the covariance matrix is obtained with the so-called NMC method (Parrish and Derber, 1992). The principle of this method is that A (or actually B) is estimated from the difference between two perturbed forward model runs. In our case, one run is driven by meteorological fields from a $24-\mathrm{h}$ forecast, while the other is driven by fields from a 48 -h forecast. The matrix $\mathbf{A}$ is split into a horizontal and a vertical part, $\mathbf{A}=\mathbf{A}_{v} \otimes \mathbf{A}_{h}$. We calculate $\mathbf{A}_{v}$ explicitly, whereas $\mathbf{A}_{h}$ is parameterised by fitting the decorrelation length scale of a Gaussian function. This procedure yields a length scale of around $500 \mathrm{~km}$. However, in our assimilation experiments we treat the error correlation length scale of the initial concentration field $L_{\boldsymbol{c}_{0}}$ as a free parameter, for which a default value of $1000 \mathrm{~km}$ is chosen (see Sect. 3). Defined in this way, the covariance is a measure of uncertainties in modelled methane related to uncertainties 
in the underlying meteorological analyses, while it neglects other sources of error.

The vertical correlations between concentration errors are illustrated in Fig. 1. The errors depend strongly on the variability in methane concentrations, since this determines how much impact a modification of the wind field has on the concentrations at a particular point. This variability is relatively high in the lower troposphere (due to emission patterns), decreases towards the troposphere, and is very high in the stratosphere.

To save calculation time, the control vector is not made up of the methane concentrations at all vertical levels, but rather of a number of vertical distributions defined by the leading eigenvectors of $\mathbf{B}_{v}$. We took 15 vertical distributions and verified that this gave nearly identical inversion results compared to taking all 25 vertical levels.

Correlations between errors in emissions and concentrations are assumed to be zero.

\subsection{Satellite data}

For a quantitative assessment of methane emissions derived from SCIAMACHY observations, it is crucial that measurement details are simulated accurately. Therefore, we attempt to model the observations as realistically as possible.

ENVISAT operates in a nearly polar, sun-synchronous orbit at an altitude of $800 \mathrm{~km}$, crossing the equator at 10:00 a.m. local time. SCIAMACHY offers a number of measurement geometries, of which the nadir mode is relevant for measuring trace gases in the troposphere. Total columns of methane have been retrieved by several groups based on different parts of the measured spectrum in the near infrared. Frankenberg et al. (2005a) used measurements from spectral channel 6 (around $1650 \mathrm{~nm}$ ), whereas Buchwitz et al. (2005) employed spectral channel 8 (around $2270 \mathrm{~nm}$ ). This paper is based on simulated observations from channel 8 , for which the ground pixel size is $120 \times 30 \mathrm{~km}$. The swath width of the SCIAMACHY measurements is $960 \mathrm{~km}$. Complete spatial coverage near the equator is achieved in six days.

Column-averaged methane mixing ratios can be obtained by normalising the total $\mathrm{CH}_{4}$ column with some well-known atmospheric trace gas column. This method has been demonstrated using $\mathrm{O}_{2}$ (Buchwitz et al., 2005) and $\mathrm{CO}_{2}$ (Frankenberg et al., 2005a). One advantage of using normalised columns is that uncertainties in surface pressure cancel out. If the window in which the reference gas is retrieved is furthermore spectrally close to the $\mathrm{CH}_{4}$ window, as is the case for $\mathrm{CO}_{2}$ in channel 6 , one also partly cancels out instrument uncertainties (slit function, calibration errors, instrument response) and radiation transport uncertainties (aerosol scattering, albedo), which would otherwise lead to systematic errors in retrieved $\mathrm{CH}_{4}$.

The precision of near-infrared methane retrievals is strongly limited by the amount of radiation that is backscattered from the Earth's surface. This is determined mainly by the albedo and the solar zenith angle (SZA). As shown below, the use of measurements partially influenced by clouds is beneficial. An additional advantage of the relative measurement approach over the direct $\mathrm{CH}_{4}$ retrieval is thus that the higher albedo of clouds boosts the signal to noise ratio, in particular over the ocean, allowing higher precision methane retrieval. The significant uncertainties in the cloud characterisation partly cancel in the retrieved relative column mixing ratio. The synthetic measurements in this study are assumed to have a random error as shown in Fig. 2. In some of the sensitivity experiments described in Sect. 3.2 the measurement error is multiplied by a constant factor without changing the dependence on albedo and SZA.

Cloud information is needed to determine the light path seen by the satellite instrument. The FRESCO algorithm (Koelemeijer et al., 2001) has been used to calculate the effective cloud fraction $f$ and cloud-top height $z_{c}$ from all available SCIAMACHY pixels in March. A known problem with the version of FRESCO used here is that it produces non-zero cloud fractions over cloud-free desert regions. Meanwhile an improved version is available that overcomes this problem. In this study, all cloud fractions over deserts that were smaller than 0.35 were set to 0 in our simulations. Figure 3 shows the resulting average cloud fraction, along with the distribution of cloud-free pixels. This figure also gives an indication of the data coverage, and shows that one orbit over the western Pacific is always missing in our dataset.

An estimate of the albedo is also needed. This is taken from a monthly surface reflectivity data set for the 2.2$2.35 \mu \mathrm{m}$ region described in Yu and Drummond (1998). Values of the surface albedo $\alpha_{s}$ range from 0.01 over water to around 0.3 over deserts. For clouds an albedo $\alpha_{c}$ of 0.5 is assumed.

The sensitivity of the tracer column retrieved from the satellite measurement to a tracer abundance at a certain height $z$ is reflected by the so-called averaging kernel AK (Rodgers, 2000; Eskes and Boersma, 2003). Here, a simplified AK is applied, which takes into account the effect of clouds:

$$
\begin{aligned}
\operatorname{AK}(z) & =1, & & \text { for } z>z_{c} ; \\
& =\frac{\alpha_{s}(1-f)}{\alpha_{s}(1-f)+\alpha_{c} f}, & & \text { for } z<z_{c} .
\end{aligned}
$$

where $f$ is the cloud fraction and $z_{c}$ is the cloud-top height. It should be noted that, apart from the effect of clouds, the real AK depends somewhat on height (Buchwitz et al., 2005). When real SCIAMACHY data will be used, these heightdependent averaging kernels, which are part of the retrieval product, can be easily applied in the assimilation.

\subsection{Setup of experiments}

We present a number of Observing System Simulation Experiments (OSSEs) (Atlas, 1997). Such experiments consist 

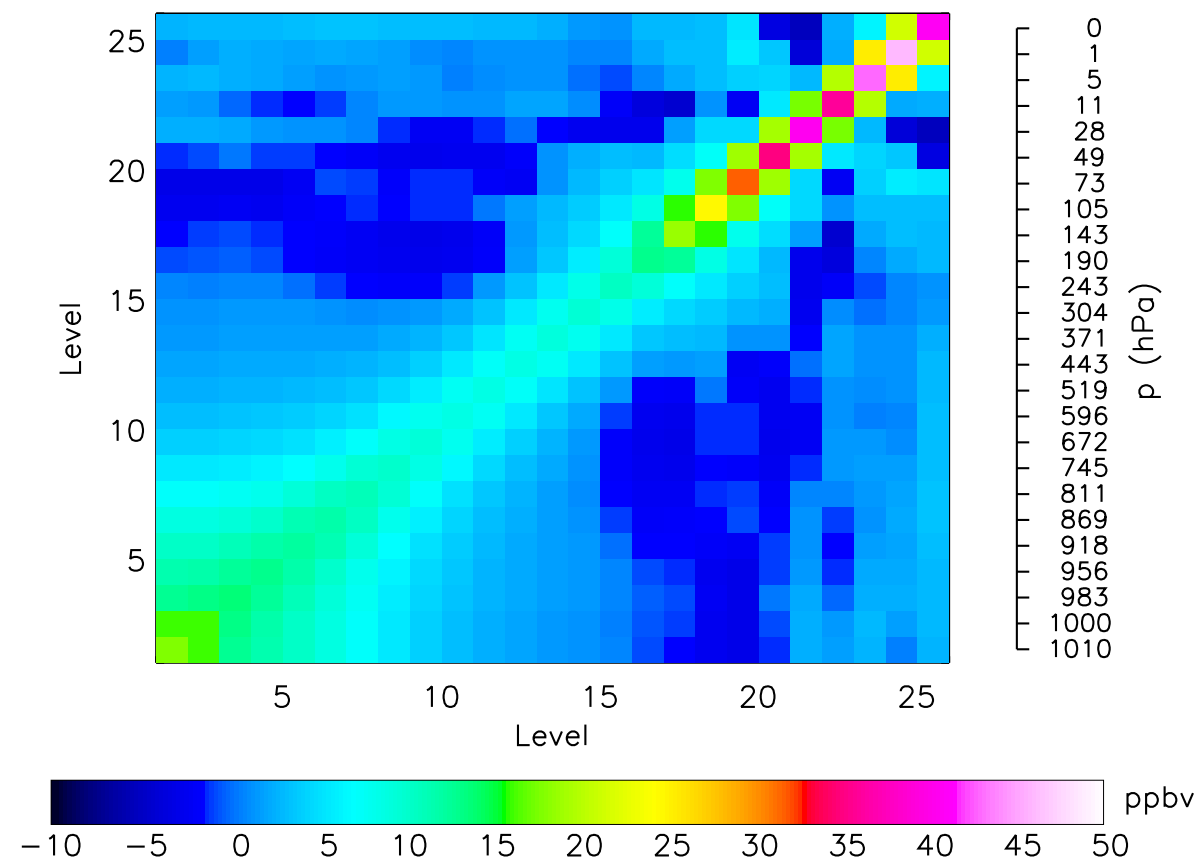

Fig. 1. Vertical correlation of errors in methane concentrations as determined with the NMC method. Shown is the square root of the elements of the background error covariance matrix $\mathbf{B}_{v}$. The pressure at the model levels is given on the right-hand side.

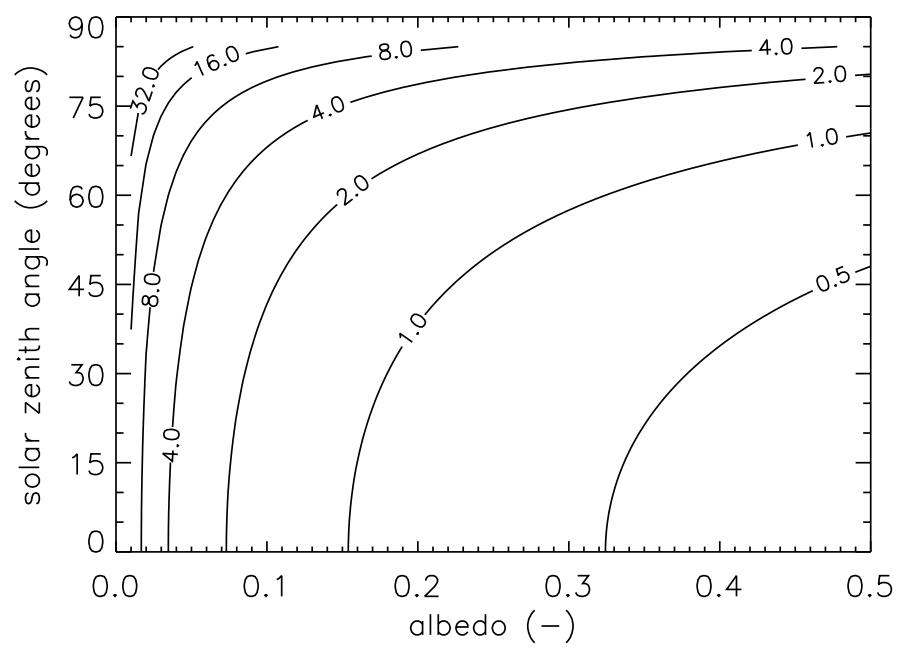

Fig. 2. Modelled percentual random error in $\mathrm{CH}_{4}$ column-averaged mixing ratio observation as a function of albedo and solar zenith angle.

of the following steps.

1. The "true" control vector $\boldsymbol{x}_{0, t}$ is defined as a perturbation to the background:

$$
x_{0, t}=x_{b}+\Delta .
$$

2. Synthetic satellite measurements are generated by sampling a free model run starting from the true control vector. This sampling takes into account the averaging kernel as given in Eq. (4), i.e.: model profiles are convoluted with the averaging kernel to obtain the columnaveraged mixing ratio. The $\mathrm{AK}$ is calculated from the "true" cloud and albedo parameters ( $f_{t}$ etc.), which are assumed to be randomly perturbed compared to the observed ones $\left(f_{o}\right.$ etc.). The random errors are assumed to be 0.1 for the cloud fraction, $50 \mathrm{hPa}$ for the cloudtop pressure, and $10 \%$ for the surface albedo. Also, the cloud parameters are restricted within a physical range. Formally, the true cloud parameters are determined as follows:

$$
\begin{aligned}
f_{t} & =\min \left[1, \max \left[0, f_{o}+0.1 \epsilon\right]\right], \\
p_{c, t} & =\min \left[p_{s}, \max \left[140, p_{c, o}+50 \epsilon\right]\right], \\
\alpha_{s, t} & =\min \left[1, \max \left[0.005, \alpha_{s, o}(1+0.1 \epsilon)\right]\right],
\end{aligned}
$$

where $p_{c}$ and $p_{s}$ are the cloud-top and surface pressure in $\mathrm{hPa}$, respectively, and $\epsilon$ is a random number drawn from the normal distribution with zero mean and unit standard deviation. To the resulting column-averaged mixing ratio a random measurement error according to Fig. 2 (using the pixel albedo, $\alpha_{s}(1-f)+\alpha_{c} f$, as input) is added.

3. The measurements are assimilated, and an optimal (a posteriori) estimate of the control vector is produced.

Comparison of the a posteriori estimate with the truth gives an indication of the success of the inversion in terms of 

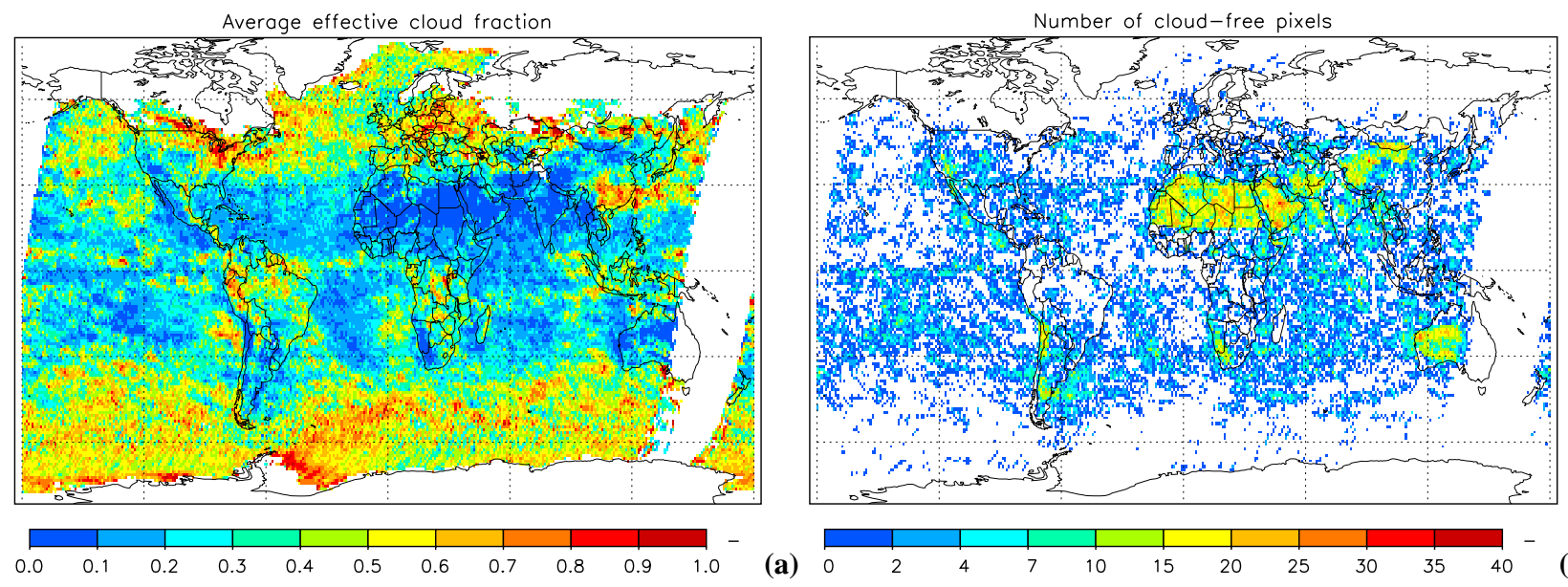

Fig. 3. Cloud information retrieved with the FRESCO algorithm from available SCIAMACHY data for March 2004 binned on $1^{\circ} \times 1^{\circ}$ grid cells. (a) Average cloud fraction. (b) Number of cloud-free $(f<0.03)$ pixels. The intervals are exclusive of the lower border and inclusive of the upper border (for example: the dark-blue colour refers to 1 or 2 measurements in a grid cell). The total number of pixels is around 667000 , of which 79000 are cloud-free.

drawing information on the control vector from the available observations. As a quantitative measure of the reduction in the $\mathrm{CH}_{4}$ emission error we use the RMS reduction factor $r$, defined as:

$r=\sqrt{\frac{\left(s_{a}-s_{t}\right)^{T}\left(s_{a}-s_{t}\right)}{\left(s_{b}-s_{t}\right)^{T}\left(s_{b}-s_{t}\right)},}$

where $s_{t}, s_{b}$, and $s_{a}$ are the true, a priori (background), and a posteriori (analysed) flux fields, respectively. With this definition, best results correspond to RMS reduction factor values approaching zero.

The random errors assumed for the cloud parameters result in a random error in observed column-averaged $\mathrm{CH}_{4}$ mixing ratios of around $10 \mathrm{ppbv}$. Moreover, the non-linearities in relations (4) and (6-8) give rise to systematic errors in the mixing ratio, which depend on the cloud parameters themselves in a complicated way. For example: the capping off of the cloud fraction at 0 leads to a negative bias in the observed methane columns for low cloud fractions. These systematic errors are relatively small ( $\sim 0.5 \mathrm{ppbv})$ but can give considerable biases in retrieved emissions, as will be discussed later.

As mentioned before, experiments have been performed for the month March 2004. Figure 4a and b show the a priori emissions and monthly-mean $\mathrm{CH}_{4}$ columns for this month, respectively. Three cases will be investigated in Sect. 3. The first consists of an increase in wetland emissions by $50 \%$ (Fig. 4c). Such an increase in monthly emissions is within the estimated uncertainty range. The effect of the enhanced emissions on the atmospheric columns after one month is only $\approx 1.5 \%$ at most (Fig. $4 \mathrm{~d}$ ). This low impact of the emissions is caused by the long lifetime of methane and poses a huge challenge to the measurements. The second case is the same except that the increase is only $25 \%$. The third case consists of a $50 \%$ increase in fossil-fuel emissions combined with a $50 \%$ decrease in waste-handling emissions. This case is illustrated in Figs. $4 \mathrm{e}$ and f. Note that the scale in panel (f) extends only half that of panel (d).

\section{Results}

\subsection{Demonstration of the method}

In this section the inverse modelling method is demonstrated. It will be shown that the assimilation system successfully retrieves information on $\mathrm{CH}_{4}$ emissions from the SCIAMACHY measurements, and that it can discriminate between errors in a priori emissions and initial concentrations.

We start with the emission perturbation consisting of a $50 \%$ increase in the wetland source (see Fig. 4c). A time window of 1 month (March 2004) is chosen. Further "standard" settings are as follows. The a priori error in emissions is assumed to be $100 \%$. The a priori error in atmospheric concentrations is as determined by the NMC method (see Fig. 1), multiplied by a factor 2 . This factor reflects the weight given to the initial concentration field, relative to the emissions, for explaining the observations. The factor 2 was chosen on the basis of a number of experiments, as will be discussed later. The error decorrelation length scales for emissions, $L_{s}$, and concentrations, $L_{c_{0}}$, are both set to $1000 \mathrm{~km}$. The motivation for these values and the sensitivity to other choices will be discussed in Sect. 3.2, where also the sensitivity of the inversion results to many other settings is investigated.

First, an idealised inversion was performed, in which the $\mathrm{CH}_{4}$ observation error was set to zero, and all pixels were assumed to be cloud-free. Furthermore, the control vector 

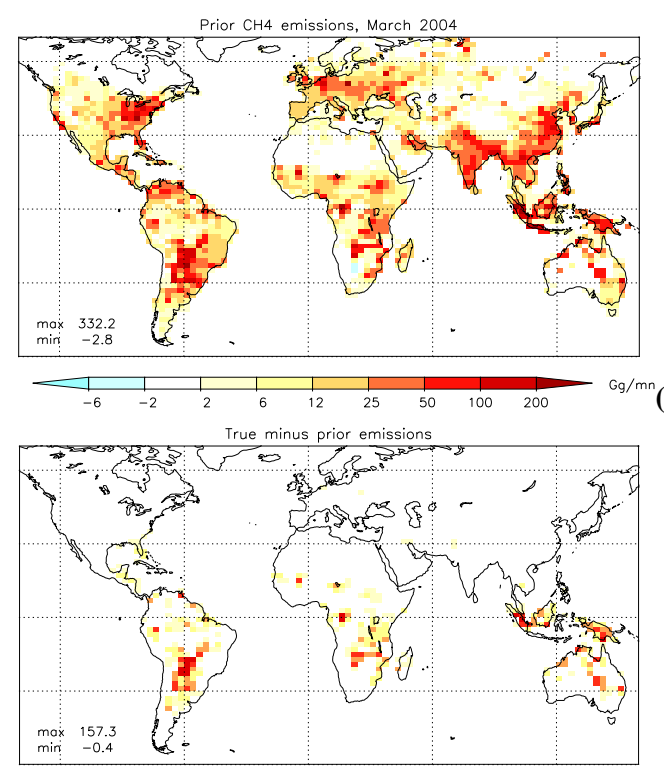

(a)
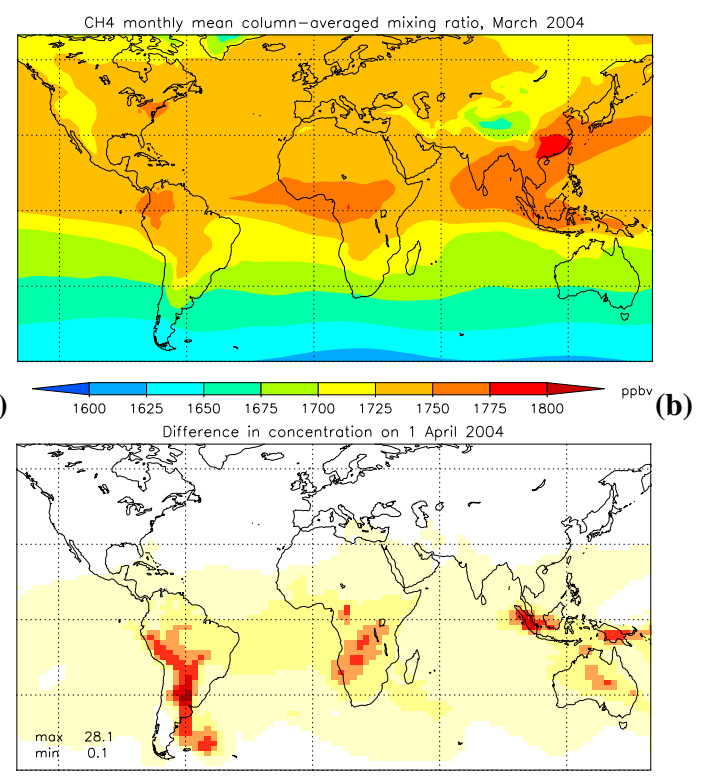

(c)
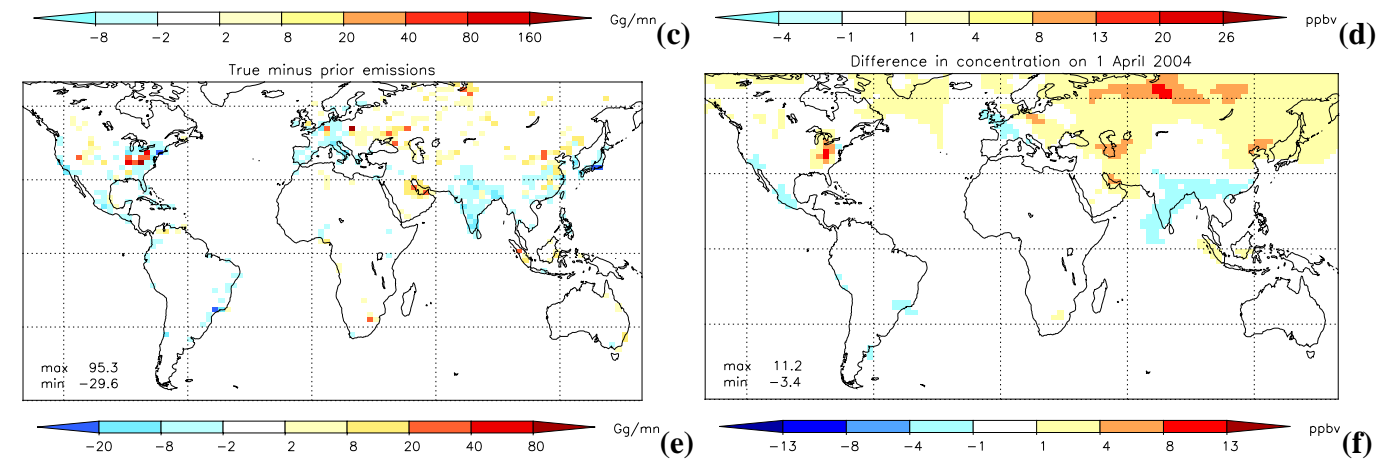

Fig. 4. Illustration of the experiments: (a) a priori $\mathrm{CH}_{4}$ emissions; (b) monthly-mean $\mathrm{CH}_{4}$ column-averaged mixing ratio; (c) true minus a priori emissions for the wetland case; (d) difference between $\mathrm{CH}_{4}$ column fields from true and a priori runs at 1 April 2004 for the wetland case; (e) as panel (c) but for the fossil-fuel/waste-handling case; (f) as panel (d) but for the fossil-fuel/waste-handling case.

was formed by the wetland emissions only. This inversion showed convergence of the cost function to nearly zero, with a reduction of the cost function gradient by a factor 500 after 20 iterations. At that point, the RMS reduction factor $r$, Eq. (9), was 0.13 and still decreasing.

Next, we turn to a reference case for realistic observations. The measurements are generated as explained in Sect. 2.4, with the $\mathrm{CH}_{4}$ observation errors as in Fig. 2. To construct the observation error covariance matrices $\mathbf{R}_{i}$, these same values are used - meaning that the $\mathrm{CH}_{4}$ observation errors are perfectly known - augmented with an error of $10 \mathrm{ppbv}$ to reflect errors in cloud parameters.

The convergence behaviour of the iterative analysis scheme is illustrated in Fig. 5. Panel (a) shows that the relative reduction in the cost function is marginal. The main reason for this is that the a priori run matches the observations already quite well. Differences between the truth and a priori runs are near zero at most locations and around $1.5 \%$ at most (Fig. 4d), which is of the order of the measurement precision. The gradient of the cost function reduces by a factor 20-30 panel (b). This is typical: the experiments presented in Sect. 3.2 have reductions in the gradient between 10 and 100. Finally, panel (c) shows the RMS reduction factor $r$, as defined in Eq. (9). It can be seen that $r$ has its minimum after 8 iterations. According to this measure, the analysis does no longer improve afterwards, although the cost function and its gradient still reach lower values. This behaviour is generally observed in our synthetic experiments, and is interpreted as follows. In the first iteration steps, the assimilation retrieves the main features in the emission field. Subsequent iterations do lead to further reductions in the cost function and its gradient (although the evolution of the gradient is often quite "wild"), but these reductions are obtained by "fitting the noise" in the observations, rather than by extracting additional information from the observations. From Fig. 4 it is clear that choosing a threshold for the cost function 
Table 2. Parameters and results of sensitivity experiments: $\Delta \boldsymbol{s}$ are perturbations in emissions (see Sect. 2.4); $\Delta \boldsymbol{c}_{0}$ are perturbations in initial concentrations (see this section); $\mathrm{f}\left(\sigma_{o}\right)$ is a multiplicative factor applied to the observation error of Fig. $2 ; \sigma_{s}$ is the relative error in the a priori emissions; $\mathrm{f}\left(\sigma_{\boldsymbol{c}_{0}}\right)$ is a multiplicative factor applied to the a priori errors in the initial concentration field as shown in Fig. 1. The result of the inversion, expressed through the RMS reduction factor $r$ of the inverted $\mathrm{CH}_{4}$ emission fields, is shown in the last column. The observational bias in experiments $5 \mathrm{a}$ to $\mathrm{c}$ was applied over a part of South America $\left(90^{\circ} \mathrm{W}-40^{\circ} \mathrm{W}, 30^{\circ} \mathrm{S}-0^{\circ} \mathrm{S}\right)$. The bias in experiments 6 a to c depends linearly on the SZA, being zero for $\mathrm{SZA}=20^{\circ}$, and has a global-mean value as indicated in the column "Note".

\begin{tabular}{|c|c|c|c|c|c|c|c|c|}
\hline Exp & Description & $\Delta s$ & $\Delta c_{0}$ & $\mathrm{f}\left(\sigma_{o}\right)$ & $\sigma_{s}(\%)$ & $\mathrm{f}\left(\sigma_{\boldsymbol{c}_{0}}\right)$ & Note & $r$ \\
\hline 1 & standard case & Fig. $4 \mathrm{c}$ & - & 1 & 100 & 2 & & 0.38 \\
\hline $2 \mathrm{a}$ & prior error in concentration field & Fig. $4 \mathrm{c}$ & Fig. 8a & 1 & 100 & 2 & & 0.43 \\
\hline $2 b$ & & Fig. $4 \mathrm{c}$ & Fig. $8 \mathrm{a}$ & 1 & 100 & 1 & & 0.44 \\
\hline $2 \mathrm{c}$ & & Fig. $4 \mathrm{c}$ & Fig. $8 \mathrm{a}$ & 1 & 100 & $10^{-3}$ & & 0.74 \\
\hline 3 & optim. emissions only & Fig. $4 \mathrm{c}$ & - & 1 & 100 & $10^{-3}$ & & 0.48 \\
\hline $4 a$ & random observation error & Fig. $4 \mathrm{c}$ & - & 0.25 & 100 & 2 & & 0.35 \\
\hline $4 \mathrm{~b}$ & & Fig. $4 \mathrm{c}$ & - & 0.5 & 100 & 2 & & 0.37 \\
\hline $4 \mathrm{c}$ & & Fig. $4 \mathrm{c}$ & - & 2 & 100 & 2 & & 0.40 \\
\hline $4 d$ & & Fig. $4 \mathrm{c}$ & - & 4 & 100 & 2 & & 0.53 \\
\hline $5 a$ & regional observation bias & Fig. $4 \mathrm{c}$ & - & 1 & 100 & 2 & $+0.2 \%$ & 0.41 \\
\hline $5 b$ & & Fig. $4 \mathrm{c}$ & - & 1 & 100 & 2 & $+0.5 \%$ & 0.61 \\
\hline $5 c$ & & Fig. $4 \mathrm{c}$ & - & 1 & 100 & 2 & $+1 \%$ & 0.87 \\
\hline $6 a$ & SZA-dependent observation bias & Fig. $4 \mathrm{c}$ & - & 1 & 100 & 2 & $-0.2 \%$ (mean) & 0.46 \\
\hline $6 b$ & & Fig. $4 \mathrm{c}$ & - & 1 & 100 & 2 & $-0.5 \%$ & 0.71 \\
\hline $6 \mathrm{c}$ & & Fig. $4 \mathrm{c}$ & - & 1 & 100 & 2 & $-1 \%$ & 1.23 \\
\hline 7 & cloud-free pixels only & Fig. $4 \mathrm{c}$ & - & 1 & 100 & 2 & only pixels with $f_{o}<0.03$ & 1.60 \\
\hline $8 \mathrm{a}$ & error in cloud parameters & Fig. $4 \mathrm{c}$ & - & 0.25 & 100 & 2 & zero error in $f, p_{c}$ and $\alpha_{s}$ & 0.27 \\
\hline $8 b$ & & Fig. $4 \mathrm{c}$ & - & 0.5 & 100 & 2 & same & 0.28 \\
\hline $8 \mathrm{c}$ & & Fig. $4 \mathrm{c}$ & - & 1 & 100 & 2 & same & 0.33 \\
\hline $8 d$ & & Fig. $4 \mathrm{c}$ & - & 2 & 100 & 2 & same & 0.40 \\
\hline $8 \mathrm{e}$ & & Fig. $4 \mathrm{c}$ & - & 4 & 100 & 2 & same & 0.49 \\
\hline $9 \mathrm{a}$ & prior error in emissions & Fig. $4 \mathrm{c}$ & - & 1 & 25 & 2 & & 0.42 \\
\hline $9 b$ & & Fig. $4 \mathrm{c}$ & - & 1 & 50 & 2 & & 0.37 \\
\hline $9 \mathrm{c}$ & & Fig. $4 \mathrm{c}$ & - & 1 & 200 & 2 & & 0.41 \\
\hline $10 \mathrm{a}$ & error correlation length scales & Fig. $4 \mathrm{c}$ & - & 1 & 100 & 2 & $L_{s}=L_{c_{0}}=500 \mathrm{~km}$ & 0.47 \\
\hline $10 \mathrm{~b}$ & & Fig. $4 \mathrm{c}$ & - & 1 & 100 & 2 & $L_{S}=500 \mathrm{~km}$ & 0.37 \\
\hline $10 \mathrm{c}$ & & Fig. $4 \mathrm{c}$ & - & 1 & 100 & 2 & $L_{s}=250 \mathrm{~km}$ & 0.52 \\
\hline 11 & distinguishing source categories & Fig. $4 \mathrm{c}$ & - & 1 & 100 & 2 & optim. only wetland source & 0.28 \\
\hline 12 & distinguishing source categories & Fig. $4 \mathrm{c}$ & - & 1 & 100 & 2 & optim. all individual sources & 0.33 \\
\hline $13 \mathrm{a}$ & halved emission perturbation & $0.5 \times$ Fig. $4 \mathrm{c}$ & - & 0.25 & 50 & 2 & & 0.42 \\
\hline $13 b$ & & $0.5 \times$ Fig. $4 \mathrm{c}$ & - & 0.5 & 50 & 2 & & 0.46 \\
\hline $13 \mathrm{c}$ & & $0.5 \times$ Fig. $4 \mathrm{c}$ & - & 1 & 50 & 2 & & 0.47 \\
\hline $13 \mathrm{~d}$ & & $0.5 \times$ Fig. $4 \mathrm{c}$ & - & 2 & 50 & 2 & & 0.53 \\
\hline $14 \mathrm{a}$ & fossil-fuel/waste-handling & Fig. $4 \mathrm{e}$ & - & 0.25 & 100 & 2 & & 0.90 \\
\hline $14 \mathrm{~b}$ & emission perturbation & Fig. $4 \mathrm{e}$ & - & 0.5 & 100 & 2 & & 0.94 \\
\hline $14 \mathrm{c}$ & & Fig. $4 \mathrm{e}$ & - & 1 & 100 & 2 & & 0.96 \\
\hline $14 \mathrm{~d}$ & & Fig. $4 \mathrm{e}$ & - & 2 & 100 & 2 & & 0.97 \\
\hline 15 & distinguishing source categories & Fig. $4 \mathrm{e}$ & - & 1 & 100 & 2 & optim. all individual sources & 0.84 \\
\hline
\end{tabular}

gradient as the convergence criterion will not give the best emission estimate in terms of Eq. (9). Therefore, the following strategy is adopted: for every experiment 20 iterations are performed. Afterwards, the iteration step for which the cost function gradient is lower than the average gradient in 8 subsequent iterations (the exact number is not crucial here), is chosen as the analysis. This criterion basically states that there is no longer a substantial decrease in the cost function gradient.
Figure 6 shows the deviation of the analysis from the true emissions for experiment 1. Comparison with the prior deviation shows that the analysis has indeed improved the emission estimate considerably (note the different colour scales in Figs. 4c and 6). RMS reduction factors for various sensitivity experiments are summarised in Table 2. The present experiment is number 1 in Table 2, and yields a value $r=0.38$. We verified that the RMS reduction factor is robust against the particular noise added to the observations. A number of 

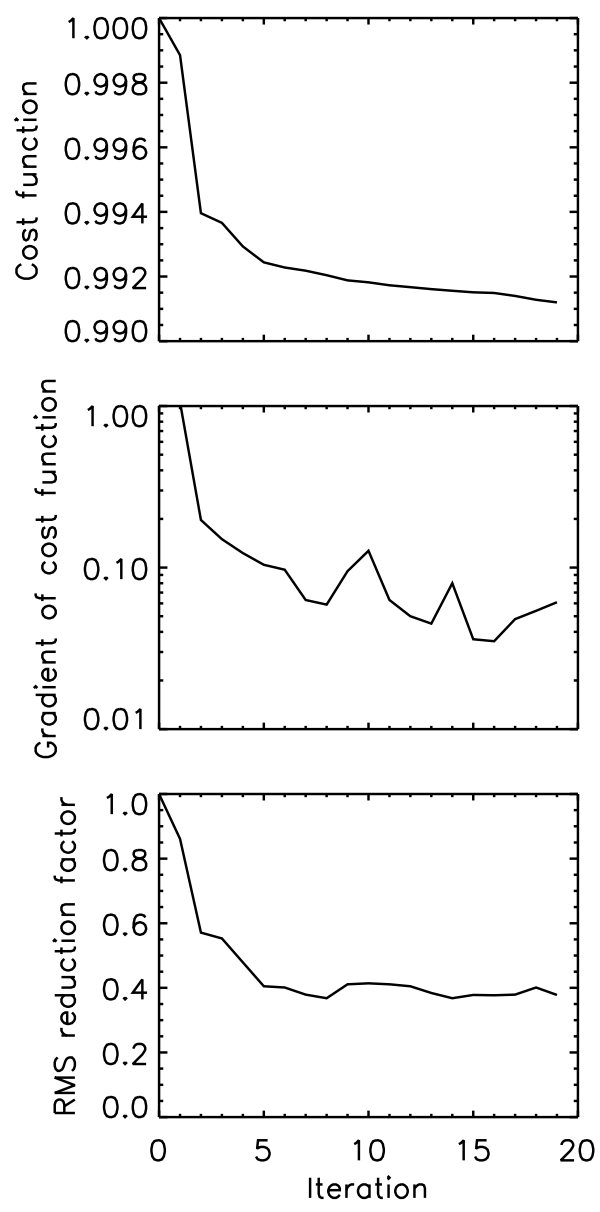

Fig. 5. Convergence of experiment 1: (a) cost function relative to its initial value; (b) gradient of the cost function relative to its initial value; and (c) RMS reduction factor as a function of the iteration step.

inversions with observations based on a different set of random numbers gave very similar values of $r$, although the spatial distribution of the analysed emission increments looked quite different.

Figure 7 shows the relative true minus a priori and analysis increment fields (panels a and $b$, respectively). The former is a "patchy" field since it follows the pattern of wetland emissions. The latter gives the incremental result of the inversion: a smooth field with spatial correlation scales of typically $1000 \mathrm{~km}$, the decorrelation length scale $L_{s}$ that has been used for the background error correlation matrix. Variations on smaller scales cannot be resolved by the inversion. On the other hand, a smaller value of $L_{s}$ - with the extreme being uncorrelated emissions - may introduce spurious small-scale structures in the analysed emission field if there is not sufficient information in the measurements to resolve emissions on this scale. This will be further investigated in Sect. 3.2.
As mentioned before, not only emissions but also concentrations are optimised in the inversion. This approach is necessary since the initial condition has a large impact on methane concentrations during the assimilation window, and errors therein will thus deteriorate the analysed emission field. To illustrate this, an inversion has been performed for a case in which the true concentration field deviated from the background (see Fig. 8a). The deviation was created by running the model in the previous month (February 2004) with perturbed emissions, in this case a $50 \%$ increase in the fossil-fuel and waste-handling sources, a 50\% decrease in the ruminants source, and a $25 \%$ decrease in the wetland source. Figure $8 \mathrm{~b}$ shows the deviation of analysed emissions from the truth when only emissions are optimised. Clearly, the system tries to explain observed high concentrations over the USA by enhanced emissions in that region, while they were actually due to an error in the initial concentration field. Similarly, the error in initial concentrations over the southernhemispheric continents leads to an underestimation of emissions. The errors in concentrations over north-west Russia do not lead to corresponding increments in the emission analysis because they are not observed (see Fig. 3).

Figures $8 \mathrm{c}$ and $\mathrm{d}$ show the result of an inversion in which both emissions and initial concentrations are optimised. Indeed, a substantial part of the errors in the initial concentration field has been recognised as such (panel c), leading to a better estimation of the emission field (panel d). The RMS reduction factors are 0.43 and 0.70 for an inversion with and without optimisation of the initial concentration field, respectively (experiments $2 \mathrm{a}$ and $\mathrm{c}$ in Table 2). This is an important result, demonstrating that the assimilation system can distinguish between errors in the initial concentration field and emissions during the month. A comparison between Figs. 8a and $\mathrm{c}$ shows that the assimiliation system does not recover the small-scale patterns of the initial concentration perturbation. For this reason, the retrieved emission field in experiment $2 \mathrm{a}$ is somewhat worse than in experiment 1.

The joint optimisation of emissions and initial concentrations thus enables the use of relatively short time windows in the inversion. On the other hand, the time frame cannot be made arbitrarily short. The inverse model draws its information on emissions from the time evolution of atmospheric concentrations. Therefore, two requirements determine the minimum length of the assimilation window. First, the time frame should be long enough that emissions cause measurable changes in the atmospheric concentrations. Second, enough observations should be available to allow the discrimination between initial concentrations and emissions. A trial inversion with one week of SCIAMACHY measurements showed that such a time frame is too short to obtain a meaningful emission estimate.

Figure 9 shows the difference in column-averaged concentration between observations and background/analysis over a part of South America. In this region the observations are lower than the background simulation during the first days of 


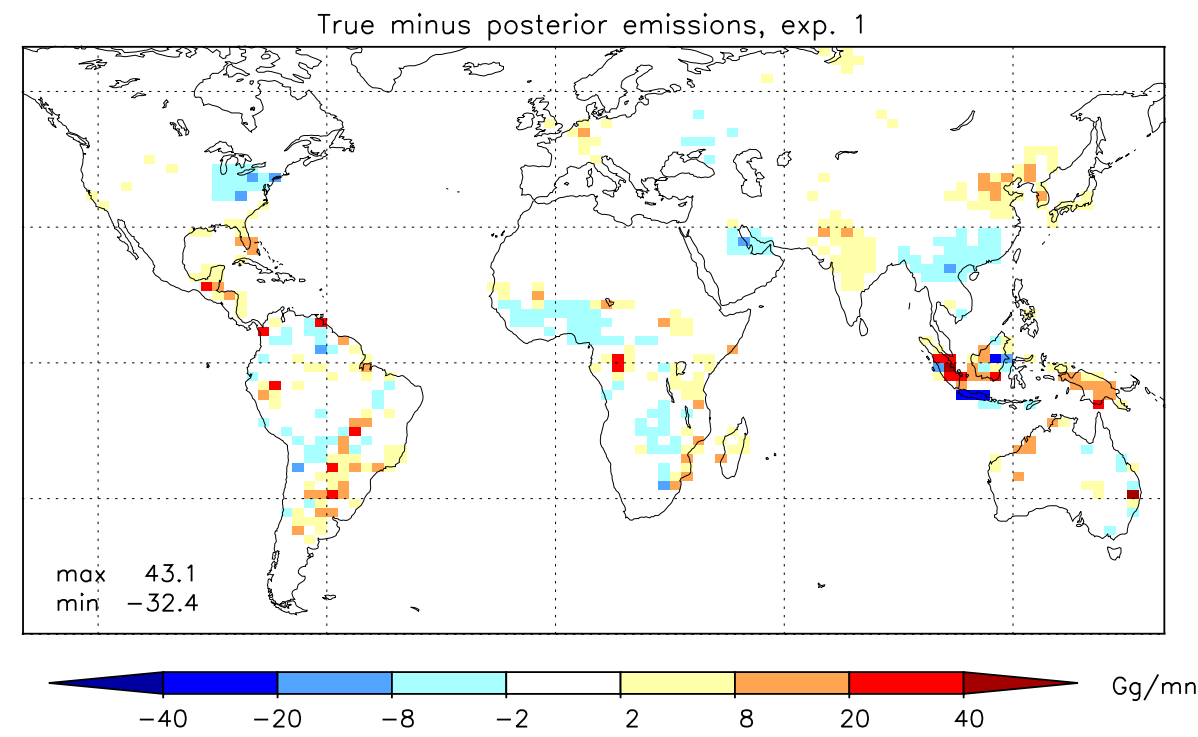

Fig. 6. True minus posterior emissions for experiment 1.

the month. After some time ( 3 to 6 days), this situation is reversed, because the true emissions are larger than the prior emissions. In experiment $2 \mathrm{a}$, the inversion manages to explain these differences relatively well in terms of a decrease in initial concentrations and an increase in emissions. In experiment $2 \mathrm{c}$, the initial concentrations cannot be adjusted, which is compensated by an underestimated emission increment. As a result, the analysed concentrations are initially too high and finally too low.

A second advantage of including the initial concentration field in the optimisation is that some systematic errors in the satellite observations can be absorbed by the corresponding part of the control vector, so that they affect the retrieved emissions only to a limited extent. As was mentioned in Sect. 2.4, the synthetic observations contain systematic biases due to the errors assumed in the cloud parameters. We performed an inversion as experiment 1 but without allowing the initial concentration field to be adjusted (experiment 3 in Table 2). Indeed, the result of this experiment is considerably poorer, with $r=0.48$ instead of 0.38 . In particular, if systematic errors are relatively constant in time and space during the assimilation window, they can be partly absorbed by changing the initial concentration field in the model. The measurement bias is then transferred to the model simulation, while the analysed emissions are relatively unaffected. In reality, many systematic errors will vary in time and space, so that the above does not work. In any case, all possible efforts should be made to remove any observation bias by careful validation, before the inverse modelling is applied. Systematic measurement errors are further discussed in Sect. 3.2.1.

\subsection{Sensitivity studies}

Several sensitivity experiments have been performed in order to investigate the impact of various parameters on the inversion result. They are summarised in Table 2. Experiments 1 to 3 have been discussed in Sect. 3.1, except for experiment $2 b$. In this experiment the a priori error in the concentrations was taken exactly as found with the NMC method. The value of $r$ is about equal to the experiment with a doubled error (2a). The ratio between a priori errors in emissions and concentrations determines the relative importance given to both parts of the control vector in the analysis of the measurements. In general, we found best results when taking a scaling factor of 2 for the concentration errors. Therefore, further experiments are performed with this value.

\subsubsection{Observation error}

Experiments 4a to d (Table 2) assess the impact of the (random) observation error on the error in retrieved emissions. The observation error - both the actual noise on the observations and the errors assumed in the covariance matrix - has been multiplied by a number of constant factors compared to Fig. 2. A decrease in the observation error leads to a decrease in the RMS reduction factor, as expected. However, on going from a multiplication factor of 2 to 0.25 , the performance improves only slightly. This suggests that when the $\mathrm{CH}_{4}$ measurements reach a certain precision, other factors start becoming dominant. One important factor is the uncertainty in cloud parameters, which will be discussed in Sect. 3.2.2.

It should be noted that the RMS reduction factors obtained depend heavily on the truth-prior perturbation applied. 


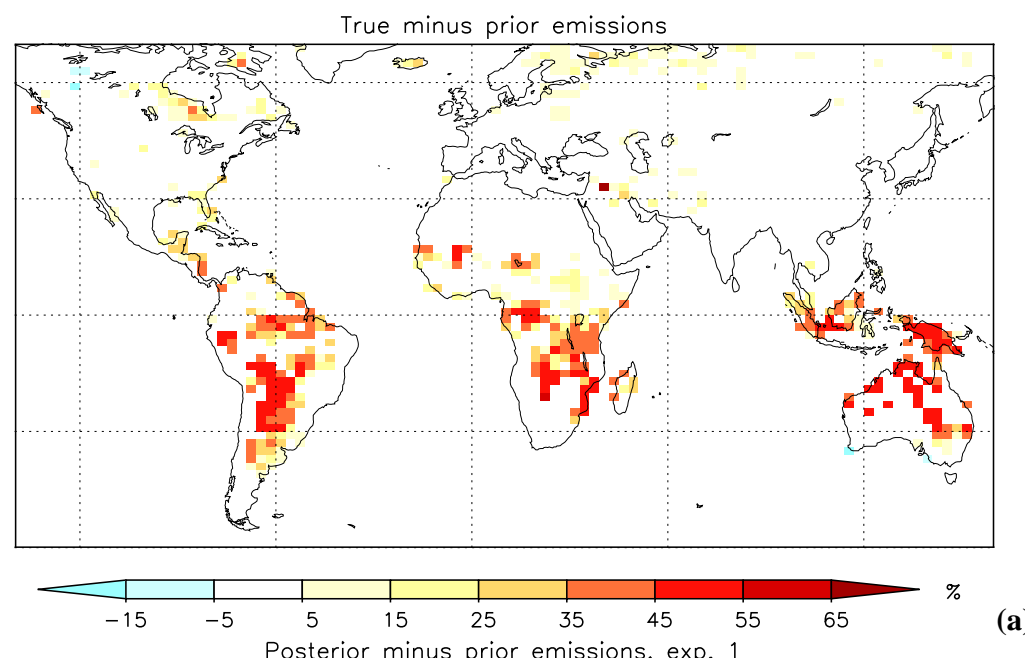

(a)

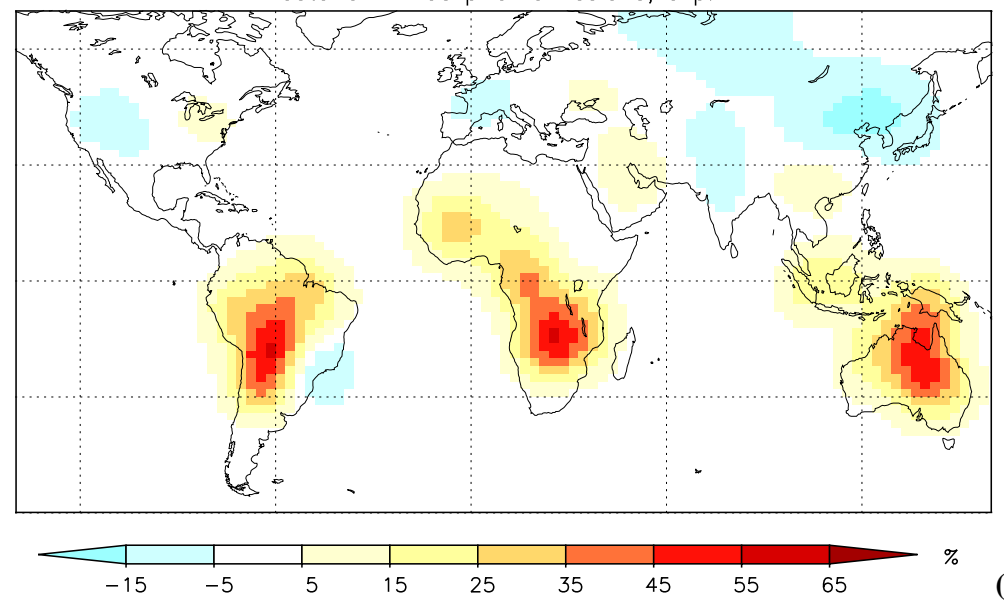

(b)

Fig. 7. Effect of prior error correlations illustrated for experiment 1: (a) percentage difference between true and a priori emissions; (b) percentage difference between a posteriori and a priori emissions.

Experiments 13a to d show results for the $25 \%$-wetland perturbation, in which the deviations of the atmospheric concentrations are half those of the reference case. As a result, the performance is worse than the corresponding experiments 1 and $4 \mathrm{a}$ to $\mathrm{c}$. Even an improvement in the measurement precision with a factor 8 cannot compensate for the decreased atmospheric signal (compare experiments $13 \mathrm{a}$ and $4 \mathrm{c}$ ).

The experiments with a 50\%-perturbation of both fossilfuel and waste handling emissions show an even worse performance, with $r$-values between 0.90 (exp. 14a) and 0.97 (exp. 14d). This has a number of reasons. (i) The absolute difference between true and a priori emissions is simply lower than for the wetland case. (ii) The main atmospheric signal is at higher northern-hemispheric latitudes, where the SZA is higher and observations are thus less precise. (iii) A considerable part of the atmospheric signal - mainly over Siberia - is not observed at all or only in the presence of high cloud cover in this particular month. (iv) The combination of a positive (fossil fuel) and a negative (waste handling) pertur- bation leads to dipole-like features in the true-prior emission field, which cannot be reproduced by an inversion employing a relatively large decorrelation length scale for the a priori errors in the emissions. This last point can be improved upon by distinguishing between different source types in the inversion, as is shown in Sect. 3.2.3.

We now turn our attention to systematic observation errors. As was mentioned in the introduction there are many potential sources of such errors. Here, two specific types of systematic errors are discussed.

First, the effect of a regional bias is investigated, which may typically be caused by the presence of aerosols or by errors in the assumed surface albedo in a particular region. In experiments $5 \mathrm{a}$ to $\mathrm{c}$, a bias has been added to the observations over South America. The impact on the RMS reduction factor depends strongly on the magnitude of the bias. While a $0.2 \%$ error may still seem acceptable, a $0.5 \%$ error is clearly not. To give an indication of the impact on the emissions: the maximum emission analysis increment in the 

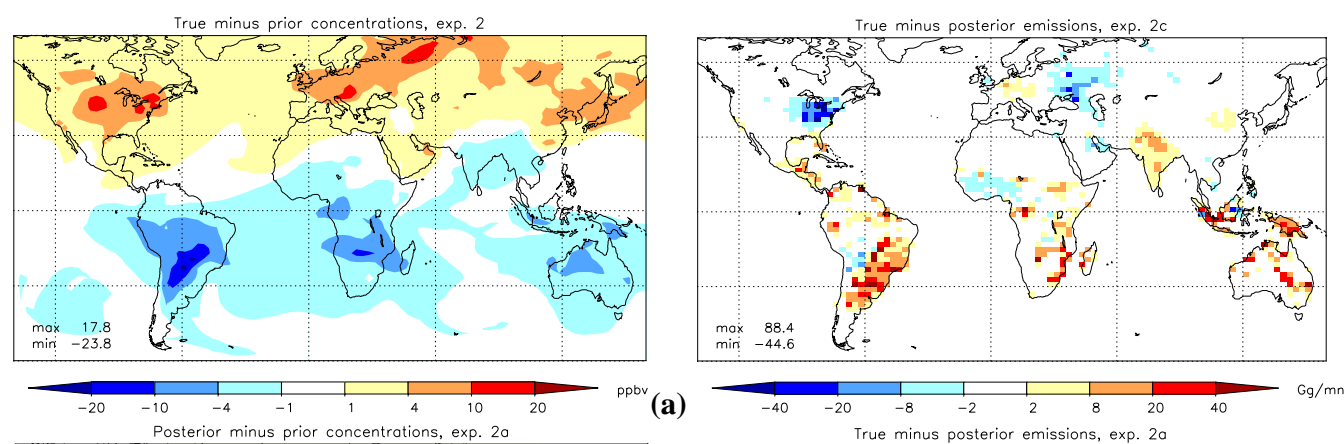

(a)
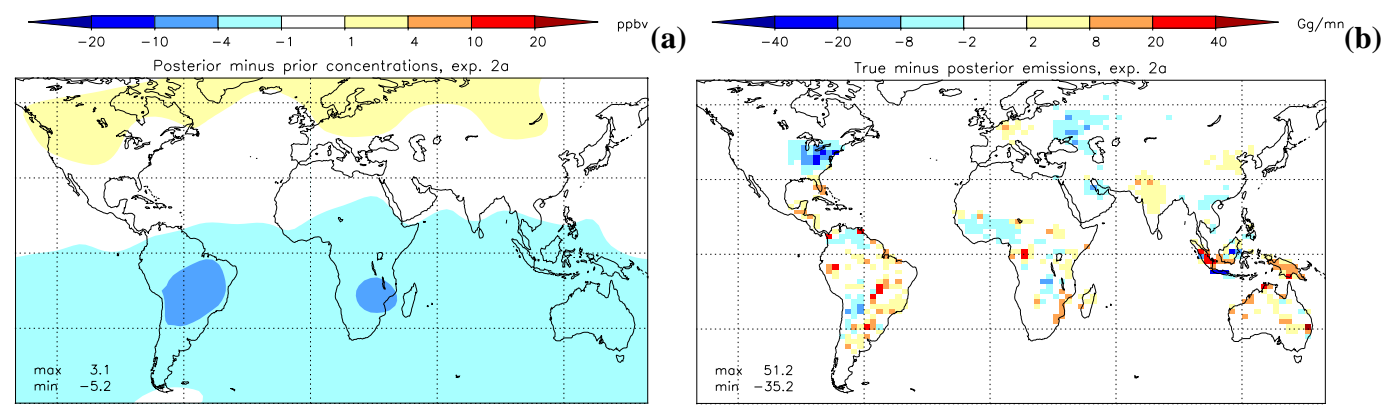

(c)

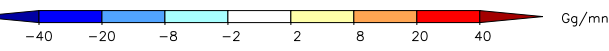

$(d)$

Fig. 8. Influence of error in initial concentrations: (a) true minus a priori initial column field, applied in experiment 2 in addition to the emission perturbation from Fig. 4c; (b) true minus posterior emissions for emission-only inversion (exp. 2c); (c) posterior minus prior initial column field for combined concentration-emission inversion (exp. 2a); (d) true minus posterior emissions for combined concentrationemission inversion (exp. 2a).

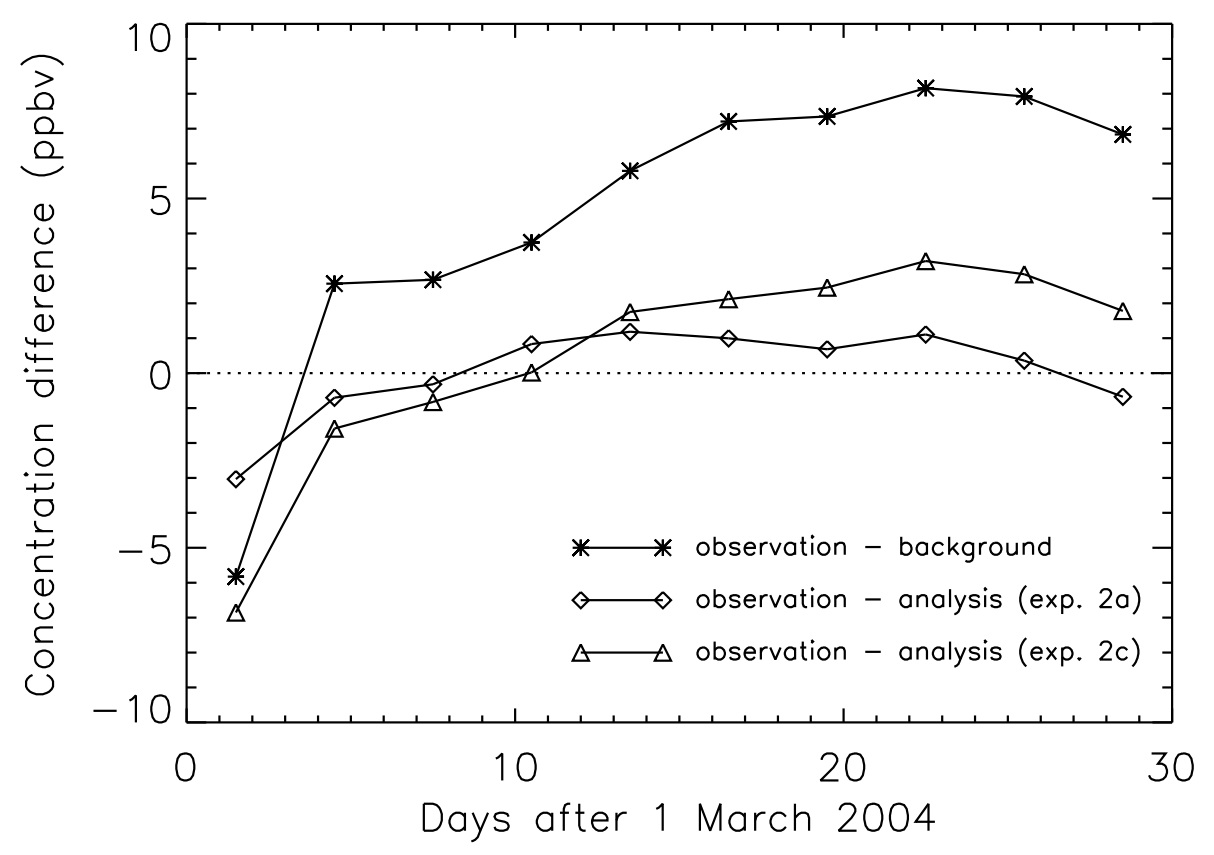

Fig. 9. Time series of observed minus background and observed minus analysed concentrations for experiments $2 \mathrm{a}$ and $2 \mathrm{c}$ over a part of South America $\left(70^{\circ} \mathrm{W}-50^{\circ} \mathrm{W}, 30^{\circ} \mathrm{S}-10^{\circ} \mathrm{S}\right)$. The measurements have been averaged over three days; each data point represents around 600 pixels. 
South-American wetland region is $77 \%, 141 \%$ and $184 \%$ for systematic errors of $0.2 \%, 0.5 \%$ and $1 \%$, respectively, while the unbiased case (exp. 1) gives $57 \%$, and the true increment is $50 \%$.

Second, we investigate the effect of an SZA-dependent bias, which may, for example, be caused by instrument calibration errors. In experiments $6 a$ to $c$, a negative bias, increasing in magnitude with the SZA, has been added to the measurements. A large part of this bias is absorbed by increments in the initial concentration field (indeed, without the inclusion of initial concentrations in the control vector the results are disastrous), but, as is clear from the RMS reduction factors listed in Table 2, the emissions are also severely affected.

It should be noted that the global performance measure $r$ gives a relatively positive view of the consequences of a regional bias, because most regions on Earth are not affected. In terms of global means, the observational bias in experiment $6 \mathrm{a}$ is ten times larger than in experiment 5a. Therefore, the $r$-values from experiments 5 and 6 should not be directly compared.

\subsubsection{Clouds}

Experiment 7 (Table 2) illustrates - for the 50\%-wetland case - what happens when only cloud-free pixels are taken into account. This leads to a large reduction in the number of observations: only $12 \%$ remain, mostly located over desert regions (see Fig. 3b). Therefore, they carry relatively little information on emissions. The result is that the imposed emission perturbation cannot be recovered at all $(r=1.60)$. A value $r>1$ signifies that the analysis is further away from the truth than the a priori. In an ideal assimilation system, with unbiased a priori fields and observations, this is not a realistic result since observations always add information to the system even if they are sparse and imprecise. However, our assimilation system is not ideal. In particular, the a priori error specification is poor, since we assume a fixed relative error for the total emission, while in fact only the wetland emissions are wrong. Section 3.2.3 contains an experiment in which only wetland emissions are optimised, indeed leading to better results.

SCIAMACHY achieves global coverage in six days, producing around five measurements per month for a given location. From an independent trajectory point of view one would need two measurements in order to derive monthly emissions in conjunction with the concentration at the start of the month. Since clouds affect $\approx 90 \%$ of the measurements, this criterion is usually not met. Therefore, it is essential to take partly cloudy pixels into account.

The use of cloudy pixels in the inversion imposes additional requirements on the quality of cloud parameters and albedo. Experiments 8a to e (Table 2) show the inversion results when perfect cloud information is assumed to be available, as opposed to the "default" uncertainties assumed in experiments 1 and $4 \mathrm{a}$ to $\mathrm{d}$. For all values of the measurement error the performance improves, but, as expected, this is most notable for the cases with the lowest errors in $\mathrm{CH}_{4}$.

\subsubsection{A priori information}

Experiments 9a to c (Table 2) show the result of different choices for the a priori error in the emission field. The best result - slightly better than in the reference experiment 1 is obtained when the a priori uncertainty is set to the actual value of the perturbation applied (50\%), suggesting that the analysis system is nicely balanced. Strengthening or relaxing the a priori constraint to uncertainties of $25 \%$ and $100 \%$, respectively, yields a slightly less favourable result. Overall, the performance appears to be not very sensitive to the precise value of the a priori error.

The emission estimates are more sensitive to the value of the a priori error decorrelation length scales of emissions, $L_{s}$, and initial concentrations, $L_{\boldsymbol{c}_{0}}$. When both are decreased from the default value of $1000 \mathrm{~km}$ to $500 \mathrm{~km}$ (experiment 10a), the RMS reduction factor increases to 0.47 . This could lead to the conclusion that there is not enough information in the measurements to allow an effective resolution of $\sim 500 \mathrm{~km}$. However, when $L_{\boldsymbol{c}_{0}}$ is kept at $1000 \mathrm{~km}$ while $L_{s}$ is reduced to $500 \mathrm{~km}$ (experiment $10 \mathrm{~b}$ ), the resulting $r$ is about equal to that of the reference case. It appears that particularly the initial concentration field needs a relatively large decorrelation length scale, since otherwise the measurement noise introduces spurious small-scale features in the analysis. For the emissions an effective resolution of $500 \mathrm{~km}$ appears to be feasible. When $L_{s}$ is further decreased to $250 \mathrm{~km}$ (experiment 10c), the RMS reduction factor becomes 0.52 , indicating that there is not sufficient information in the measurements to resolve the fluxes on this resolution.

There are a number of reasons why the setup used so far cannot perfectly reproduce the truth $(r=0)$. These include the limited number of measurements and the error in $\mathrm{CH}_{4}$ and cloud-parameter measurements. Another reason is that the complete emission field is optimised with a single error correlation length scale, whereas, the truth - prior perturbation concerns only wetland emissions. Suppose we knew that all prior emissions except those of wetlands were correct, then we could optimise the wetland emissions only. This is done in experiment 11 (Table 2), and leads to a very good performance $(r=0.28)$. In reality, one does not possess such knowledge. Still, information on errors (and error correlations) in the different source categories can be used in the inversion. Experiment 12 (Table 2) is an inversion of all source categories, meaning that the control vector is constituted by the emissions from the different categories, which are all assumed to have the same a priori error of $100 \%$ and to be mutually independent. This approach also gives an improvement with respect to the reference case. The advantage of optimising different source categories is particularly clear in experiment 15 (compare with exp. 14c). The combined 
positive and negative increments of the fossil-fuel and wastehandling emissions can be reproduced better if these fields are distinguished in the inversion.

\section{Conclusions and outlook}

In this paper we have shown the utility of four-dimensional variational assimilation for the optimisation of methane emissions on the basis of observations from the SCIAMACHY satellite instrument. Sources are estimated over a time window of one month, which is short compared to the atmospheric residence time of methane. A consequence of this short time window is that errors in initial concentrations cannot be neglected. We have solved this problem by jointly optimising the emissions and the initial concentration field. The feasibility of the method has been demonstrated using Observing System Simulation Experiments (OSSEs).

Subsequently, a large number of OSSEs have been analysed in order to assess the utility of SCIAMACHY measurements for methane source attribution. The sensitivity of the source estimate to (random) $\mathrm{CH}_{4}$ observation errors, errors introduced by the presence of clouds, and the specification of a priori errors has been investigated. From these experiments the following conclusions can be drawn.

- SCIAMACHY observations at a precision of 1 to $2 \%$ (single measurement) can contribute considerably to uncertainty reduction in methane source strengths. The temporal and spatial scales that can be resolved are estimated to be 1 month and $500 \mathrm{~km}$, respectively. Achieving such rather small spatial scales, SCIAMACHY will be a very useful addition to the surface measurement network, which primarily constrains the (sub)continental scales.

- Systematic observation errors well below $1 \%$ have a dramatic impact on the quality of the derived emission fields. There are many possible sources of such systematic errors in methane retrievals, either caused by the instrument itself, by the retrieval algorithm or by the characterisation of the scene. Identification and removal of these biases is crucial.

- It is essential to take partly cloudy pixels into account for emission estimates in order to achieve sufficient spatial coverage. The relative importance of cloudy pixels compared to cloud-free pixels will depend on the pixel size and coverage of the satellite instrument (SCIAMACHY in our case). Future satellite instruments will have higher overpass frequencies and much smaller ground pixels (like, for example, the OCO instrument for $\mathrm{CO}_{2}$ described in Crisp et al., 2004), and consequently a relatively larger number of cloud-free pixels.
- The effective cloud fraction and cloud-top height of the partially cloudy satellite footprints as well as the surface albedo should be retrieved as accurately as possible. According to our findings, errors in these parameters pose in some cases a larger limitation for the source estimation than errors in the methane measurement itself.

Recent SCIAMACHY $\mathrm{CH}_{4}$ retrievals have an estimated precision of 1.5 to $2 \%$ (Frankenberg et al., 2005a). This kind of precision is sufficient for direct comparisons with models and identification of some major large-scale uncertainties in the emission inventories used in the models. Future satellite instruments may improve upon the performance of SCIA$\mathrm{MACHY}$ in the following respects:

- Instrument design: a better spectral resolution for the methane absorption spectrometer and a more sensitive and stable detector would be both desirable and feasible when applying current technology.

- Measurement strategy: smaller pixels and pointing at cloud-free scenes will increase the number of cloudfree pixels. Such pixels contain most information on the boundary layer, where the signal of surface emissions is largest.

- Characterisation of the measurement scene: accurate knowledge on clouds and aerosols is a prerequisite for a proper interpretation of the methane measurements. Such information can be obtained, for instance, by measuring the $\mathrm{O}_{2}$-A band with high spectral resolution, and by including dedicated high-resolution cloud and aerosol imagers.

An assumption commonly made in inverse modelling, and also in this study, is that the description of tracer transport is perfect. However, transport model errors can be considerable, and can have a large impact on the derived emission fields (e.g., Engelen et al., 2002). Nevertheless, there are two reasons why transport errors may be less harmful for the inversion of satellite data compared to surface measurements. First, satellite data have a far better spatial coverage, so that the signature of emissions at the observation location is less influenced by transport and errors therein. Second, errors in vertical transport, which is notoriously difficult to model, do in first order not affect the total column amount as observed by the satellite. It is an important advantage that SCIAMACHY-type measurements in the near-infrared are indeed sensitive to the whole column, as opposed to measurements in the thermal infrared, which are hardly sensitive to the boundary layer, and for which the interpretation is thus hampered by uncertainties in vertical transport.

Concerning the inverse modelling system, several extensions will be considered in the future:

- Surface observations at remote locations contain important information on the methane budget at continental 
to global scales. Optimal future assimilation systems should thus include both satellite and surface observations.

- Presently, mismatches between model and observations are attributed to errors in methane sources (and initial concentrations). However, model uncertainties are partly caused by errors in the modelling of the sinks. A generalised approach may be formulated in which the $\mathrm{OH}$ field is added to the 4D-var control vector together with a realistic error estimate.

- A detailed and realistic modelling of the error covariances of the initial concentrations and emissions is crucial for a successful inversion. Regarding errors in the initial concentrations (mainly transport errors): once real satellite data are considered, analysis of the observation minus model departures gives additional information on error correlation lengths scales. Regarding errors in prior emissions: the models producing the prior emissions should be used to provide realistic estimates of errors and their spatial correlations for the different source categories.

- In synthetic experiments the truth is known, and the inversion result can be evaluated against this truth. In case of real measurements a posteriori error estimates should be provided, which can be calculated as outlined in Müller and Stavrakou (2005).

In summary, we have presented a method for the estimation of methane concentrations and emissions from SCIAMACHY measurements. This method is not restricted to methane but can also be applied to carbon dioxide or shorterlived trace gases such as carbon monoxide and nitrogen oxides. Furthermore, OSSE type of experiments with 4D-Var systems as described here will be important for assessing the potential benefit of future satellite instruments.

Acknowledgements. We thank J. Drummond and A. G. Straume for making available the surface reflectivity database, R. van der A for processing the FRESCO data for SCIAMACHY, and A. J. M. Segers for support with the NMC calculations. This study was financially supported by the European Commission's project EVERGREEN (5th FP on Energy, environment and sustainable development, contract number EVG1-CT-2002-00079). SCIAMACHY is a joint German-Dutch-Belgian project funded by the national space agencies DLR, NIVR and BUSOC.

Edited by: W. E. Asher

\section{References}

Atlas, R.: Observing System Simulation Experiments: methodology, examples and limitations, in: Impact of various observing systems on Numerical Weather Prediction, edited by: Pailleux, J., Proceedings of CGC/WMO Workshop, Geneva, 7-9 April
1997, World Weather Watch Technical Report No 18, WMO/TD No. 868, 155-163, 1997.

Bergamaschi, P., Krol, M., Dentener, F., Vermeulen, A., Meinhardt, F., Graul, R., Ramonet, M., Peters, W., and Dlugokencky, E. J.: Inverse modelling of national and European $\mathrm{CH}_{4}$ emissions using the atmospheric zoom model TM5, Atmos. Chem. Phys., 5, 2431-2460, 2005.

Bovensmann, H., Burrows, J. P., Buchwitz, M., Frerick, J., Noel, S., Rozanov, V. V., Chance, K. V., and Goede, A. P. H.: SCIAMACHY: Mission objectives and measurement modes, J. Atmos. Sci., 56, 127-150, 1999.

Bregman, B., Segers, A., Krol, M., Meijer, E., and van Velthoven, P.: On the use of mass-conserving wind fields in chemistrytransport models, Atmos. Chem. Phys., 3, 447-457, 2003.

Buchwitz, M., de Beek, R., Burrows, J. P., Bovensmann, H., Warneke, T., Notholt, J., Meirink, J. F., Goede, A. P. H., Bergamaschi, P., Körner, S., Heimann, M., and Schulz, A.: Atmospheric methane and carbon dioxide from SCIAMACHY satellite data: initial comparison with chemistry and transport models, Atmos. Chem. Phys., 5, 941-962, 2005.

Butler, T. M., Simmonds, I., and Rayner, P. J.: Mass balance inverse modelling of methane in the 1990s using a chemistry transport model, Atmos. Chem. Phys., 4, 2561-2580, 2004.

Chen, Y.-H.: Estimation of methane and carbon dioxide surface fluxes using a 3-D global atmospheric chemical transport model, $\mathrm{PhD}$ thesis, Mass. Inst. of Technol., Cambridge, 2003.

Clerbaux, C., Hadji-Lazaro, J., Turquety, S., Mégie, G., and Coheur, P.-F.: Trace gas measurements from infrared satellite for chemistry and climate applications, Atmos. Chem. Phys., 3, 14951508, 2003.

Courtier, P., Thépaut, J.-N., and Hollingsworth, A.: A strategy for operational implementation of 4D-Var, using an incremental approach, Quart. J. Roy. Meteorol. Soc., 120, 1367-1387, 1994.

Crisp, D., Atlas, R. M., Breon, F.-M., Brown, L. R., Burrows, J. P., Ciais, P., Connor, B. J., Doney, S. C., Fung, I. Y., Jacob, D. J., Miller, C. E., O'Brien, D., Pawson, S., Randerson, J. T., Rayner, P., Salawitch, R. J., Sander, S. P., Sen, B., Stephens, G. L., Tans, P. P., Toon, G. C., Wennberg, P. O., Wofsy, S. C., Yung, Y. L., Kuang, Z., Chudasama, B., Sprague, G., Weiss, B., Pollock, R., Kenyon, D., and Schroll, S.: The Orbiting Carbon Observatory (OCO) mission, Adv. Space Res., 34, 700-709, 2004.

Dentener, F., Van Weele, M., Krol, M., Houweling, S., and Van Velthoven, P.: Trends and inter-annual variability of methane emissions derived from 1979-1993 global CTM simulations, Atmos. Chem. Phys., 3, 73-88, 2003.

Elbern, H. and Schmidt, H.: Chemical 4D variational data assimilation and its numerical implications for case study analyses, in: Atmospheric Modeling, edited by: Chock, D. P. and Carmichael, G. R., IMA volumes in Mathematics and its Applications, vol. 130, 165-184, Springer, 2002.

Engelen, R. J., Denning, A. S., Gurney, K. R., and TransCom3 modelers: On error estimation in atmospheric $\mathrm{CO}_{2}$ inversions, J. Geophys. Res., 107, 4635, doi:10.1029/2002JD002195, 2002.

Eskes, H. J. and Boersma, K. F.: Averaging kernels for DOAS totalcolumn satellite retrievals, Atmos. Chem. Phys., 3, 1285-1291, 2003.

Eskes, H. J., Piters, A. J. M., Levelt, P. F., Allaart, M. A. F., and Kelder, H. M.: Variational assimilation of GOME total-column ozone satellite data in a $2 \mathrm{D}$ latitude-longitude tracer-transport 
model, J. Atmos. Sci., 56, 3560-3572, 1999.

Fisher, M. and Lary, D. J.: Lagrangian four-dimensional variational data assimilation of chemical species, Quart. J. Roy. Meteorol. Soc., 121, 1681-1704, 1995.

Frankenberg, C., Meirink, J. F., van Weele, M., Platt, U., and Wagner, T.: Assessing methane emissions from global space-borne observations, Science, 308, 1010-1014, 2005.

Frankenberg, C., Platt, U., and Wagner, T.: Iterative maximum a posteriori (IMAP)-DOAS for retrieval of strongly absorbing trace gases: Model studies for $\mathrm{CH}_{4}$ and $\mathrm{CO}_{2}$ retrieval from near infrared spectra of SCIAMACHY onboard ENVISAT, Atmos. Chem. Phys., 5, 9-22, 2005.

Gilbert, J. C. and Lemaréchal, C.: Some numerical experiments with variable-storage quasi-Newton algorithms, Math. Progr., 45, 407-435, 1989.

Gloudemans, A. M. S., Schrijver, H., Kleipool, Q., van den Broek, M. M. P., Straume, A. G., Lichtenberg, G., van Hees, R. M., Aben, I., and Meirink, J. F.: The impact of SCIAMACHY nearinfrared instrument calibration on $\mathrm{CH}_{4}$ and $\mathrm{CO}$ total columns, Atmos. Chem. Phys., 5, 2369-2383, 2005.

Goede, A. P. H., Aarts, H. J. M., van Baren, C., Burrows, J. P., Chance, K. V., Hoekstra, R., Hölzle, E., Pitz, W., Schneider, W., Smorenburg, C., Visser, H., and de Vries, J.: Sciamachy instrument design, Adv. Space Res., 11, 243-246, 1991.

Hein, R., Crutzen, P. J., and Heimann, M.: An inverse modelling approach to investigate the global atmospheric methane cycle, Global Biogeochem. Cycles, 11, 43-76, 1997.

Houweling, S., Dentener, F. J., and Lelieveld, J.: The impact of nonmethane hydrocarbon compounds on tropospheric photochemistry, J. Geophys. Res., 103, $10673-10$ 696, 1998.

Houweling, S., Kaminski, T., Dentener, F. J., Lelieveld, J., and Heimann, M.: Inverse modelling of methane sources and sinks using the adjoint of a global transport model, J. Geophys. Res., 104, 26 137-26 160, 1999.

Houweling, S., Breon, F.-M., Aben, I., Rödenbeck, C., Gloor, M., Heimann, M., and Ciais, P.: Inverse modeling of $\mathrm{CO}_{2}$ sources and sinks using satellite data: A synthetic inter-comparison of measurement techniques and their performance as a function of space and time, Atmos. Chem. Phys., 4, 523-538, 2004.

IPCC: Climate change 2001: The scientific basis, edited by: Houghton, J. T., Ding, Y., Griggs, D. J., et al., Cambridge University Press, UK and New York, NY, USA, 2001.

Kaminski, T., Rayner, P. J., Heimann, M., and Enting, I. G.: On aggregation errors in atmospheric transport inversions, J. Geophys. Res., 106, 4703-4715, 2001.

Koelemeijer, R. B. A., Stammes, P., De Haan, J. F., and Hovenier, J. W.: A fast method for retrieval of cloud parameters using oxygen A-band measurements from the Global Ozone Monitoring Experiment, J. Geophys. Res., 106, 3475-3490, 2001.

Lelieveld, J., Crutzen, P. J., and Dentener, F. J.: Changing concentration, lifetime and climate forcing of atmospheric methane, Tellus, 50, 128-150, 1998.

Martin, R. V., Jacob, D. J., Chance, K., Kurosu, T. P., Palmer, P. I., and Evans, M. J.: Global inventory of nitrogen oxide emissions constrained by space-based observations of $\mathrm{NO}_{2}$ columns, J. Geophys. Res., 108, 4537, doi:10.1029/2003JD003453, 2003.

Matthews, E., Fung, I., and Lerner, J.: Methane emission from rice cultivation: Geographic and seasonal distribution of cultivated areas and emissions, Global Biogeochem. Cycles, 1, 61-
86, 1987.

Mikaloff Fletcher, S. E. M., Tans, P. P., Bruhwiler, L. M., Miller, J. B., and Heimann, M.: $\mathrm{CH}_{4}$ sources estimated from atmospheric observations of $\mathrm{CH}_{4}$ and its ${ }^{13} \mathrm{C} /{ }^{12} \mathrm{C}$ isotopic ratios: 1. Inverse modeling of source processes, Global Biogeochem. Cycles, 18, doi:10.1029/2004GB002223, 2004a.

Mikaloff Fletcher, S. E. M., Tans, P. P., Bruhwiler, L. M., Miller, J. B., and Heimann, M.: $\mathrm{CH}_{4}$ sources estimated from atmospheric observations of $\mathrm{CH}_{4}$ and its ${ }^{13} \mathrm{C} /{ }^{12} \mathrm{C}$ isotopic ratios: 2. Inverse modeling of $\mathrm{CH}_{4}$ fluxes from geographical regions, Global Biogeochem. Cycles, 18, doi:10.1029/2004GB002224, 2004b.

Müller, J.-F. and Stavrakou, T.: Inversion of $\mathrm{CO}$ and $\mathrm{NO}_{\mathrm{x}}$ emissions using the adjoint of the IMAGES model, Atmos. Chem. Phys., 5, 1157-1186, 2005.

Olivier, J., Peters, J., Granier, C., Pétron, G., Müller, J. F., and Wallens, S.: Present and future surface emissions of atmospheric compounds, POET Report 2, EU project EVK2-1999-00011, 2003.

Olivier, J. G. J., Bouwman, A. F., Berdowski, J. J. M., Veldt, C., Bloos, J. P. J., Visschedijk, A. J. H., Van der Maas, C. W. M., and Zandveld, P. Y. J.: Sectoral emission inventories of greenhouse gases on a per country basis as well as $1 \times 1$, Env. Sci. Policy, 2, 241-263, 1999.

Parrish, D. F. and Derber, J. C.: The National Meteorological Center's spectral statistical-interpolation analysis system, Mon. Wea. Rev., 120, 1747-1763, 1992.

Pétron, G., Granier, C., Khattatov, B., Yudin, V., Lamarque, J.-F., Emmons, L., Gille, J., and Edwards, D. P. Monthly CO surface sources inventory based on the 2000 2001 MOPITT satellite data, Geophys. Res. Lett., 31, L21107, doi:10.1029/2004GL020560, 2004

Peylin, P., Rayner, P. J., Bousquet, P., Carouge, C., Hourdin, F., Heinrich, P., Ciais, P., and AEROCARB contributors: Daily $\mathrm{CO}_{2}$ flux estimates over Europe from continuous atmospheric measurements: 1, inverse methodology, Atmos. Chem. Phys., 5, 3173-3186, 2005.

Randel, W. J., Wu, F., Russel III, J. M., Roche, A., and Waters, J. W.: Seasonal cycles and QBO variations in stratospheric $\mathrm{CH}_{4}$ and $\mathrm{H}_{2} \mathrm{O}$ observed in UARS HALOE data, J. Atmos. Sci., 55, 163-185, 1998

Rayner, P. J., Law, R. M., O’Brien, D. M., Butler, T. M., and Dilley, A. C.: Global observations of the carbon budget, 3, Initial assessment of the impact of satellite orbit, scan geometry, and cloud on measuring $\mathrm{CO}_{2}$ from space, J. Geophys. Res., 107, 4557, doi:10.1029/2001JD000618, 2002.

Ridgwell, A. J., Marshall, S. J., and Gregson, K.: Consumption of atmospheric methane by soils: A process-based model, Global Biogeochem. Cycles, 13, 59-70, 1999.

Rodgers, C. D.: Inverse methods for atmospheric sounding - theory and practice, Series on atmospheric, oceanic and planetary physics, World Scientific Publishing, Singapore, 2000.

Sanderson, M. G.: Biomass of termites and their emissions of methane and carbon dioxide: A global database, Global Biogeochem. Cycles, 10, 543-557, 1996.

Talagrand, O. and Courtier, P.: Variational assimilation of meteorological observations with the adjoint vorticity equation. I: Theory, Quart. J. Roy. Meteorol. Soc., 113, 1311-1328, 1987. 
Van Aardenne, J. A., Dentener, F. J., Klein Goldewijk, C. G. M., Lelieveld, J., and Olivier, J. G. J.: A $1 \times 1$ degree resolution data set of historical anthropogenic trace gas emissions for the period 1890-1990, Global Biogeochem. Cycles, 15, 909-928, 2001.

Walter, B. P., Heimann, M., and Matthews, E.: Modeling modern methane emissions from natural wetlands: 1 . Model description and results, J. Geophys. Res., 106, 34 189-34 206, 2001.
Yu, Z. Z. and Drummond, J. R.: A global surface reflectivity data set for the 2.2-2.35 $\mu \mathrm{m}$ region, Int. J. Remote Sensing, 19, 331-344, 1998. 